\title{
On the Control of Automotive Traction PEM Fuel Cell Systems
}

\author{
Ahmed Al-Durra ${ }^{1}$, Stephen Yurkovich ${ }^{2}$ and Yann Guezennec ${ }^{2}$ \\ ${ }^{1}$ Department of Electrical Engineering, The Petroleum Institute, Abu Dhabi \\ ${ }^{2}$ Center for Automotive Research, The Ohio State University \\ 930 Kinnear Road, Columbus, $\mathrm{OH} 43212$ \\ ${ }^{1}$ United Arab Emirates \\ ${ }^{2} U S A$
}

\section{Introductin}

A fuel cell (FC) is an electro-chemical device that converts chemical energy to electrical energy by combining a gaseous fuel and oxidizer. Lately, new advances in membrane material, reduced usage of noble metal catalysts, and efficient power electronics have put the fuel cell system under the spotlight as a direct generator for electricity (Pukrushpan, Stefanopoulou \& Peng, 2004a). Because they can reach efficiencies of above $60 \%$ (Brinkman, 2002),(Davis et al., 2003) at normal operating conditions, Proton Exchange Membrane (PEM) fuel cells may represent a valid choice for automotive applications in the near future (Thijssen \& Teagan, 2002), (Bernay et al., 2002).

Compared to internal combustion engines (ICEs) or batteries, fuel cells (FCs) have several advantages. The main advantages are efficiency, low emissions, and dual use technology. FCs are more efficient than ICEs, since they directly convert fuel energy to electrical energy, whereas ICEs need to convert the fuel energy to thermal energy first, then to mechanical energy. Due to the thermal energy involved, the ICE conversion of energy is limited by the Carnot Cycle, not the case with FCs (Thomas \& Zalbowitz, 2000). Fuel cells are considered zero emission power generators if pure hydrogen is used as fuel.

The PEM fuel cell consists of two electrodes, an anode and a cathode, separated by a polymeric electrolyte membrane. The ionomeric membrane has exclusive proton permeability and it is thus used to strip electrons from hydrogen atoms on the anode side. The protons flow through the membrane and react with oxygen to generate water on the cathode side, producing a voltage between the electrodes (Larminie \& Dicks, 2003). When the gases are pressurized, the fuel cell efficiency is increased, and favorable conditions result for smooth fluid flow through the flow channels (Yi et al., 2004). Pressurized operation also allows for better power density, a key metric for automotive applications. Furthermore, the membrane must be humidified to operate properly, and this is generally achieved through humidification of supplied air flow (Chen \& Peng, 2004). Modern automotive fuel cell stacks operate around $80^{\circ} \mathrm{C}$ for optimal performance (EG\&G-Technical-Services, 2002),(Larminie \& Dicks, 2003).

For such efficient operation, a compressor must supply pressurized air, a humidification system is required for the air stream, possibly a heat exchanger is needed to feed pressurized hot air at a temperature compatible with the stack, and a back pressure valve is required to control system pressure. A similar setup is required to regulate flow and pressure on 
the hydrogen side. Since the power from the fuel cell is utilized to drive these systems, the overall system efficiency drops. From a control point of view, the required net power must be met with the best possible dynamic response while maximizing system efficiency and avoiding oxygen starvation. Therefore, the system must track trajectories of best net system efficiency, avoid oxygen starvation (track a particular excess air ratio), whereas the membrane has to be suitably humidified while avoiding flooding. This can only be achieved through a coordinated control of the various available actuators, namely compressor, anode and cathode back pressure valves and external humidification for the reactants.

Because the inherently coupled dynamics of the subsystems mentioned above create a highly nonlinear behavior, control is typically accomplished through static off-line optimization, appropriate design of feed-forward commands and a feedback control system. These tasks require a high-fidelity model and a control-oriented model. Thus, the first part of this chapter focuses on the nonlinear model development in order to obtain an appropriate structure for control design.

After the modeling section, the remainder of this chapter focuses on control aspects. Obtaining the desired power response requires air flow, pressure regulation, heat, and water management to be maintained at certain optimal values according to each operating condition. Moreover, the fuel cell control system has to maintain optimal temperature, membrane hydration, and partial pressure of the reactants across the membrane in order to avoid harmful degradation of the FC voltage, which reduces efficiency (Pukrushpan, Stefanopoulou \& Peng, 2004a). While stack pressurization is beneficial in terms of both fuel cell voltage (stack efficiency) and of power density, the stack pressurization (and hence air pressurization) must be done by external means, i.e., an air compressor. This component creates large parasitic power demands at the system level, with $10-20 \%$ of the stack power being required to power the compressor under some operating conditions which can considerably reduce the system efficiency. Hence, it is critical to pressurize the stack optimally to achieve best system efficiency under all operating conditions. In addition, oxygen starvation may result in a rapid decrease in cell voltage, leading to a large decrease in power output, and "torque holes" when used in vehicle traction applications (Pukrushpan, Stefanopoulou \& Peng, 2004b).

To avoid these phenomena, regulating the oxygen excess ratio in the FC is a fundamental goal of the FC control system. Hence, the fuel cell system has to be capable of simultaneously changing the air flow rate (to achieve the desired excess air beyond the stoichiometric demand), the stack pressurization (for optimal system efficiency), as well as the membrane humidity (for durability and stack efficiency) and stack temperature. All variables are tightly linked physically, as the realizable actuators (compressor motor, back-pressure valve and spray injector or membrane humidifier) are located at different locations in the systems and affect all variables simultaneously. Accordingly, three major control subsystems in the fuel cell system regulate the air/fuel supply, the water management, and the heat management. The focus of this paper will be solely on the first of these three subsystems in tracking an optimum variable pressurization and air flow for maximum system efficiency during load transients for future automotive traction applications.

There have been several excellent studies on the application of modern control to fuel cell systems for automotive applications; see, for example, (Pukrushpan, Stefanopoulou \& Peng, 2004a), (Pukrushpan, Stefanopoulou \& Peng, 2004b), (Domenico et al., 2006), (Pukrushpan, Stefanopoulou \& Peng, 2002), (Al-Durra et al., 2007), (Al-Durra et al., 2010), and (Yu et al., 2006). In this work, several nonlinear control ideas are applied to a multi-input, 


\begin{tabular}{|c|c|}
\hline$A_{f c}$ & Cell active area $\left[\mathrm{cm}^{2}\right]$ \\
\hline$F$ & Faraday constant $\left[\frac{\mathrm{C}}{\mathrm{mol}}\right]$ \\
\hline$i$ & Cell current density $\left[\frac{\mathrm{A}}{\mathrm{cm} \mathrm{m}^{2}}\right]$ \\
\hline$I$ & Cell current $[\mathrm{A}]$ \\
\hline$M$ & Molecular weight $\left[\frac{\mathrm{kg}}{\mathrm{mol}}\right]$ \\
\hline$n$ & Angular speed $[\mathrm{rpm}]$ \\
\hline$n_{e}$ & Number of electrons $[-]$ \\
\hline$N$ & Number of cells $[-]$ \\
\hline$p$ & Pressure in the volumes $[\mathrm{bar}]$ \\
\hline$R$ & Gas constant $\left[\frac{\mathrm{bar} \cdot \mathrm{m}^{3}}{\mathrm{kgK}}\right]$ \\
\hline$\overline{\mathrm{R}}$ & Universal gas constant $\left[\frac{\mathrm{bar} \cdot \mathrm{m}^{3}}{\mathrm{molK}}\right]$ \\
\hline$T$ & Temperature $[\mathrm{K}]$ \\
\hline$V$ & Volume $\left[\mathrm{m}^{3}\right]$ \\
\hline$\omega$ & Specific humidity $[-]$ \\
\hline$W$ & Mass flow rate $\left[\frac{\mathrm{kg}}{\mathrm{s}}\right]$ \\
\hline$\mu$ & Fuel utilization coefficient \\
\hline
\end{tabular}

Table 1. Model nomenclature

multi-output (MIMO) PEM FC system model, to achieve good tracking responses over a wide range of operation. Working from a reduced order, control-oriented model, the first technique uses an observer-based linear optimum control which combines a feed-forward approach based on the steady state plant inverse response, coupled to a multi-variable LQR feedback control. Following this, a nonlinear gain-scheduled control is described, with enhancements to overcome the fast variations in the scheduling variable. Finally, a rule-based, output feedback control design is coupled with a nonlinear feed-forward approach. These designs are compared in simulation studies to investigate robustness to disturbance, time delay, and actuators limitations. Previous work (see, for example, (Pukrushpan, Stefanopoulou \& Peng, 2004a), (Domenico et al., 2006), (Pukrushpan, Stefanopoulou \& Peng, 2002) and references therein) has seen results for single-input examples, using direct feedback control, where linearization around certain operating conditions led to acceptable local responses. The contributions of this work, therefore, are threefold: Control-oriented modeling of a realistic fuel cell system, extending the range of operation of the system through gain-scheduled control and rule-based control, and comparative studies under closed loop control for realistic disturbances and uncertainties in typical operation.

\section{PEM fuel cell system model}

Having a control-oriented model for the PEM-FC is a crucial first step in understanding the system behavior and the subsequent design and analysis of a model-based control system. In this section the model used throughout the chapter is developed and summarized, whereas the interested reader is referred to (Domenico et al., 2006) and (Miotti et al., 2006) for further details. Throughout, certain nomenclature and notation (for variable subscripts) will be adopted, summarized in Tables 1 and 2.

A high fidelity model must consist of a structure with an air compressor, humidification chambers, heat exchangers, supply and return manifolds and a cooling system. Differential equations representing the dynamics are supported by linear/nonlinear algebraic equations 


\begin{tabular}{|c|c|}
\hline$a n$ & Anode \\
\hline$c a$ & Cathode \\
\hline$c m p$ & Compressor \\
\hline$D$ & Derivative \\
\hline$d a$ & Dry air \\
\hline$f c$ & Fuel cell \\
\hline$H_{2}$ & Hydrogen \\
\hline$i n$ & Inlet conditions \\
\hline$I$ & Integrative \\
\hline mem & Membrane \\
\hline$N_{2}$ & Nitrogen \\
\hline out & Outlet conditions \\
\hline $\mathrm{O}_{2}$ & Oxygen \\
\hline$P$ & Proportional \\
\hline$r m$ & Return manifold \\
\hline$s m$ & Supply manifold \\
\hline vap & Vapor \\
\hline
\end{tabular}

Table 2. Subscript notation

(Kueh et al., 1998). For control design, however, only the primary critical dynamics are considered; that is, the slowest and fastest dynamics of the system, i. e. the thermal dynamics associated with cold start and electrochemical reactions, respectively, are neglected. Consequently, the model developed for this study is based on the following assumptions: i) spatial variations of variables are neglected ${ }^{1}$, leading to a lumped-parameter model; ii) all cells are considered to be lumped into one equivalent cell; iii) output flow properties from a volume are equal to the internal properties; iv) the fastest dynamics are not considered and are taken into account as static empirical equations; v) all the volumes are isothermal.

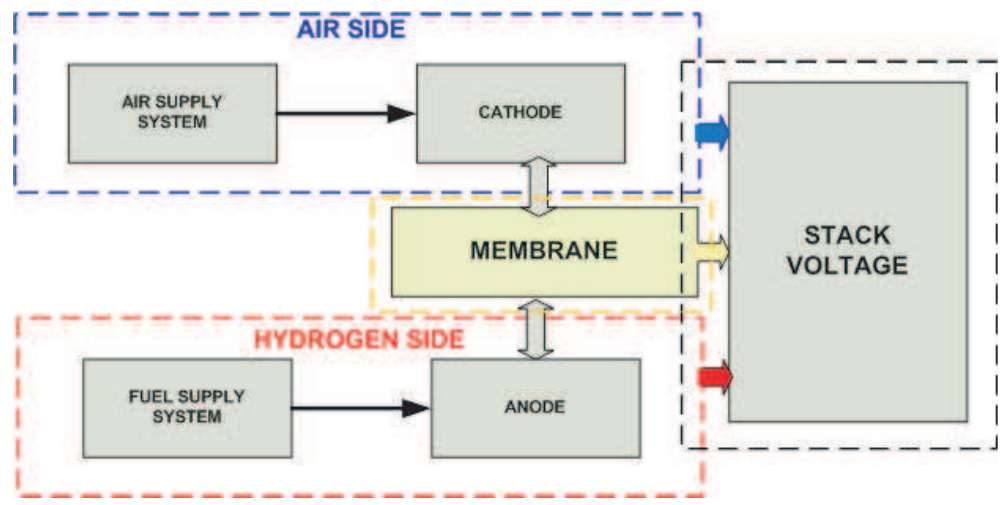

Fig. 1. Fuel cell system schematic.

An equivalent scheme of the fuel cell system model is shown in Figure 1, where four primary blocks are evident: the air supply, the fuel delivery, the membrane behavior and the stack

\footnotetext{
${ }^{1}$ Note: spatial variations are explicitly accounted for in finding maps used by this model obtained from an extensive 1+1D model (see Section 2.3)
} 
voltage performance. In what follows, the primary blocks are described in more detail. The state variables of the overall control-oriented model are chosen to be the physical quantities listed in Table 3.

\subsection{Air supply system}

The air side includes the compressor, the supply and return manifolds, the cathode volume, the nozzles between manifolds and cathode and the exhaust valve. Since pressurized reactants increase fuel cell stack efficiency, a screw compressor has been used to pressurize air into the fuel cell stack (Guzzella, 1999). The screw type compressor provides high pressure at low air flow rate. The compressor and the related motor have been taken into account as a single, comprehensive unit in order to describe the lumped dynamics of the system to a reference speed input. The approach followed for the motor-compressor model differs from the published literature on this topic. Commonly, thermodynamics and heat transfer lead to the description of the compressor behavior, while standard mathematical models define the DC or AC motors inertial and rotational dynamics. The compressor/motor assembly has been defined by means of an experimental test bench of the compressor-motor pair including a screw type compressor, coupled to a brushless DC motor through a belt and a pulley mechanism. Using the system Identification toolbox in Matlab ${ }^{T M}$, an optimization routine to maintain stability and minimum phaseness, different time based techniques have been investigated to closely match the modeled and the experimental responses. This was accomplished with an optimization routine that explored different pole-zero combinations in a chosen range. Finally, a two-pole, two-zero Auto Regressive Moving Average eXtended (ARMAX) model was identified, described by

$$
\frac{n_{c p}}{n_{c m d}}=\frac{-3.96 \cdot 10^{-5} s^{2}+0.528 s+567.5}{s^{2}+9.624 s+567.8}
$$

where $n_{c p}$ is the speed of the compressor and $n_{c m d}$ is the speed commanded. Moreover, the motor compressor assembly model simulates and computes the mass flow rate from the compressor via a static map depending on pressure and compressor speed.

For the air side, a supply and a return manifold was represented with mass balance and pressure calculation equations (Pukrushpan, 2003). Dry air and vapor pressure in the supply

\begin{tabular}{|l|}
\hline State Variables \\
\hline \hline 1. Pressure of $\mathrm{O}_{2}$ in the cathode \\
\hline 2. Pressure of $\mathrm{H}_{2}$ in the anode \\
\hline 3. Pressure of $\mathrm{N}_{2}$ in the cathode \\
\hline 4. Pressure of cathode vapor \\
\hline 5. Pressure of anode vapor \\
\hline 6. Pressure of supply manifold vapor in the cathode \\
\hline 7. Pressure of supply manifold dry air in the cathode \\
\hline 8. Pressure of cathode return manifold \\
\hline 9. Pressure of anode return manifold \\
\hline 10. Pressure of anode supply manifold \\
\hline 11. Water injected in the cathode supply manifold \\
\hline 12. Angular acceleration of the compressor \\
\hline 13. Angular velocity of the compressor \\
\hline
\end{tabular}

Table 3. State variables for the control-oriented model. 
manifold can be described as follows ((Kueh et al., 1998) (Pukrushpan, Stefanopulou \& Peng, 2002)):

$$
\begin{aligned}
& \frac{d p_{d a}}{d t}=\frac{R_{d a} T_{s m, c a}}{V_{s m, c a}}\left(W_{d a, \text { in }}-W_{d a, o u t}\right) \\
& \frac{d p_{v a p}}{d t}=\frac{R_{v a p} T_{s m, c a}}{V_{s m, c a}}\left(W_{\text {vap }, \text { in }}+W_{\text {vap }, \text { inj }}-W_{\text {vap }, \text { out }}\right)
\end{aligned}
$$

The inlet flows denoted by subscript in represent the mass flow rates coming from the compressor. Outlet mass flow rates are determined by using the nonlinear nozzle equation for compressible fluids (Heywood, 1998):

$$
W_{\text {out }}= \begin{cases}\frac{C_{d} A_{t} p_{u p}}{\sqrt{R T_{u p}}}\left(\frac{p_{d w w}}{p_{u p}}\right)^{1 / \gamma} \sqrt{\frac{2 \gamma}{\gamma-1}\left(1-\left(\frac{p_{d w}}{p_{u p}}\right)\right)^{\frac{\gamma-1}{\gamma}}} \\ \text { if } \frac{p_{d w w}}{p_{u p}}>\left(\frac{2}{\gamma+1}\right)^{\frac{\gamma}{\gamma-1}} \\ \frac{C_{t} p_{u p}}{\sqrt{R T_{u p}}} \sqrt{\gamma}\left(\frac{2}{\gamma+1}\right)^{\frac{\gamma+1}{2(\gamma-1)}} & \text { if } \frac{p_{d w w}}{p_{u p}} \leq\left(\frac{2}{\gamma+1}\right)^{\frac{\gamma}{\gamma-1}}\end{cases}
$$

where $p_{d w}$ and $p_{u p}$ are the downstream and upstream pressure, respectively, and $R$ is the gas constant related to the gases crossing the nozzle.

Many humidification technologies are possible for humidifying the air (and possibly) hydrogen streams ranging from direct water injection through misting nozzles to membrane humidifier; their detailed modeling is beyond the scope of this work and very technology-dependent. Hence, a highly simplified humidifier model is considered here, where the quantity of water injected corresponds to the required humidification level for a given air flow rate (at steady state), followed by a net first order response to mimic the net evaporation dynamics. Similar models have been used for approximating fuel injection dynamics in engines where the evaporation time constant is an experimentally identified variable which depends on air flow rate and temperature. For this work, the evaporation time constant is kept constant at $\tau=1 \mathrm{~s}$. The humidifier model can be summarized by the following equations:

$$
\begin{aligned}
& W_{i n j, \mathrm{com}}=W_{d a, i n}\left(\omega_{o u t}-\omega_{i n}\right) \\
& \dot{W}_{i n j}=W_{i n j, c o m}-W_{i n j}
\end{aligned}
$$

where $W_{i n j, c o m}$ is the commanded water injection, $\omega$ is the specific humidity, $W_{d a, i n}$ is the dry air and $W_{i n j}$ is the water injection.

The mass flow rate leaving the supply manifold enters the cathode volume, where a mass balance for each species (water vapor, oxygen, nitrogen) has been considered (Pukrushpan, Stefanopulou \& Peng, 2004):

$$
\begin{aligned}
\frac{d p_{\text {vap }}}{d t}= & \frac{R_{\text {vap }} T_{c a}}{V_{c a}}\left(W_{\text {vap }, \text { in }}-W_{\text {vap }, \text { out }}+W_{\text {vap }, \text { mem }}+\right. \\
& \left.+W_{\text {vap }, \text { gen }}\right) \\
\frac{d p_{\mathrm{O}_{2}}}{d t}= & \frac{R_{\mathrm{O}_{2}} T_{c a}}{V_{c a}}\left(W_{\mathrm{O}_{2}, \text { in }}-W_{\mathrm{O}_{2}, \text { out }}-W_{\mathrm{O}_{2}, \text { reacted }}\right) \\
\frac{d p_{\mathrm{N}_{2}}}{d t}= & \frac{R_{\mathrm{N}_{2}} T_{c a}}{V_{c a}}\left(W_{N_{2}, \text { in }}-W_{\mathrm{N}_{2}, \text { out }}\right)
\end{aligned}
$$


In the equations above, $W_{\text {vap,mem }}$ indicates the vapor mass flow rate leaving or entering the cathode through the membrane, whereas $W_{\text {vap,gen }}$ and $W_{O_{2} \text {,reacted }}$ are related to the electrochemical reaction representing the vapor generated and the oxygen reacted, respectively. Moreover, $p$ is the partial pressure of each element and thus the cathode pressure is given by

$$
p_{c a}=p_{\text {vap }}+p_{\mathrm{O}_{2}}+p_{\mathrm{N}_{2}}
$$

The gases leaving the cathode volume are collected inside the return manifold which has been modeled using an overall mass balance for the moist air:

$$
\frac{d p_{r m}}{d t}=\frac{R_{d a} T_{r m, c a}}{V_{r m, c a}}\left(W_{a i r, i n}-W_{a i r, o u t}\right)
$$

In order to control the pressure in the air side volumes, an exhaust valve has been applied following the same approach of Equation (3) where the cross sectional area may be varied accordingly to a control command.

\subsection{Fuel side}

As seen for the air side, three volumes have been taken into account: anode, supply and return manifolds. Indeed, no humidification system has been applied to the fuel side, thus leading to hydrogen inlet relative humidity equal to zero. Due to the lack of incoming vapor into the hydrogen flow, the supply manifold equation is given by (Arsie et al., 2005)

$$
\frac{d p_{H_{2}}}{d t}=\frac{R_{H_{2}} T_{s m, a n}}{V_{s m, a n}}\left(W_{H_{2}, \text { in }}-W_{H_{2}, o u t}\right)
$$

where $W_{H_{2}, \text { in }}$ is the hydrogen inlet flow supplied by a fuel tank which is assumed to have an infinite capacity and an ideal control capable of supplying the required current density. The delivered fuel depends on the stoichiometric hydrogen and is related to the utilization coefficient in the anode $\left(u_{H_{2}}\right)$ according to

$$
W_{H_{2}, \text { in }}=A_{f c} N \frac{i \cdot M_{H_{2}}}{n_{e} F} \mu_{H_{2}}
$$

In Equation (9), $A_{f c}$ is the fuel cell active area and $N$ is the number of cells in the stack; the fuel utilization coefficient $\mu_{\mathrm{H}_{2}}$ is kept constant and indicates the amount of reacted hydrogen. The outlet flow from the supply manifold, $W_{H_{2}, \text { out }}$, is determined through the nozzle Equation (3). As previously done for the cathode, the mass balance equation is implemented for the anode:

$$
\begin{aligned}
& \frac{d p_{\text {vap }}}{d t}=\frac{R_{\text {vap }} T_{a n}}{V_{\text {an }}}\left(W_{\text {vap }, \text { in }}-W_{\text {vap }, \text { mem }}-W_{\text {vap }, \text { out }}\right) \\
& \frac{d p_{\mathrm{H}_{2}}}{d t}=\frac{R_{\mathrm{H}_{2}} T_{\text {an }}}{V_{\text {an }}}\left(W_{\mathrm{H}_{2}, \text { in }}-W_{\mathrm{H}_{2}, \text { out }}-W_{\mathrm{H}_{2}, \text { reacted }}\right)
\end{aligned}
$$

where $W_{\text {vap,in }}$ is the inlet vapor flow set to zero by assumption, $W_{\text {vap,mem }}$ is the vapor flow crossing the membrane and $W_{\text {vap out }}$ represents the vapor flow collecting in the return manifold through the nozzle (Equation 3). For the return manifold, the same approach of Equation (7) is followed.

\subsection{Embedded membrane and stack voltage model}

Because the polymeric membrane regulates and allows mass water transport toward the electrodes, it is one of the most critical elements of the fuel. Proper membrane hydration 
and control present challenges to be solved in order to push fuel cell systems toward mass commercialization in automotive applications.

Gas and water properties are influenced by the relative position along both the electrodes and the membrane thickness. Although a suitable representation would use partial differential equations, the requirement for fast computation times presents a significant issue to consider. Considering also the difficulties related to the identification of relevant parameters in representing the membrane mass transport and the electrochemical phenomena, static maps are preferred to the physical model.

Nevertheless, in order to preserve the accuracy of a dimensional approach, a static map is utilized with a 1+1-dimensional, isothermal model of a single cell with 112 Nafion membrane. The 1+1D model describes system properties as a function of the electrodes length, accounting for an integrated one dimensional map, built as a function of the spatial variations of the properties across the membrane. The reader is referred to (Ambühl et al., 2005) and (Mazunder, 2003) for further details.

For the model described here, two 4-dimensional maps have been introduced: one describing the membrane behavior, the other one performing the stack voltage. The most critical variables affecting system operation and its performance have been taken into account as inputs for the multi-dimensional maps:

- current density;

- cathode pressure;

- anode pressure;

- cathode inlet humidity.

A complete operating range of the variables above has been supplied to the 1+1-dimensional model, in order to investigate the electrolyte and cell operating conditions and to obtain the corresponding water flow and the single cell voltage, respectively, starting from each set of inputs. Thus, the membrane map outputs the net water flow crossing the electrolyte towards the anode or toward the cathode and it points out membrane dehydration or flooding during cell operation. Figure 2 shows the membrane water flow behavior as a function of the current density and the pressure difference between the electrodes, fixing cathode pressure and relative humidity.

On the other side, the stack performance map determines the single cell voltage and efficiency, thus also modeling the electrochemical reactions. As previously done, the cell voltage behavior may be investigated, keeping constant two variables and observing the dependency on the others (Figure 3).

\subsection{Model parameters}

A $60 \mathrm{~kW}$ fuel system model is the subject of this work, with parameters and geometrical data obtained from the literature (Rodatz, 2003),(Pukrushpan, 2003) and listed in Table 4.

\subsection{Open loop response}

The fuel cell model of this study is driven by the estimated current rendered from demanded power. Based on the current profile, different outputs will result from the membrane and stack voltage maps. However, to see the overall effect of the current, a profile must be specified for the compressor and manifold valves on both sides. In order to test the model developed, simple current step commands are applied to the actuators, which are the return manifolds 


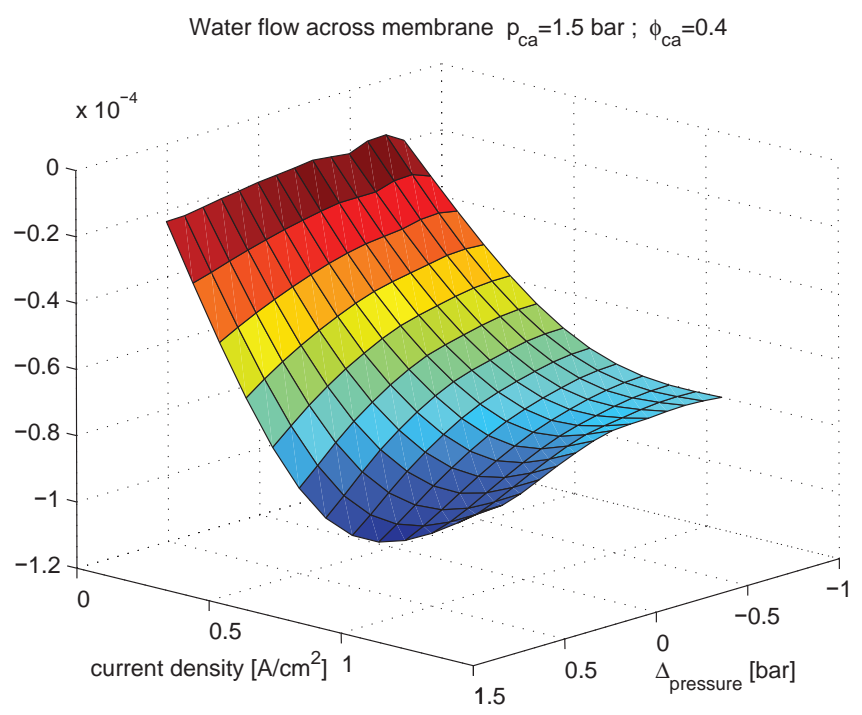

Fig. 2. Membrane water flux as a function of current density and pressure difference at constant cathode pressure and relative humidity.

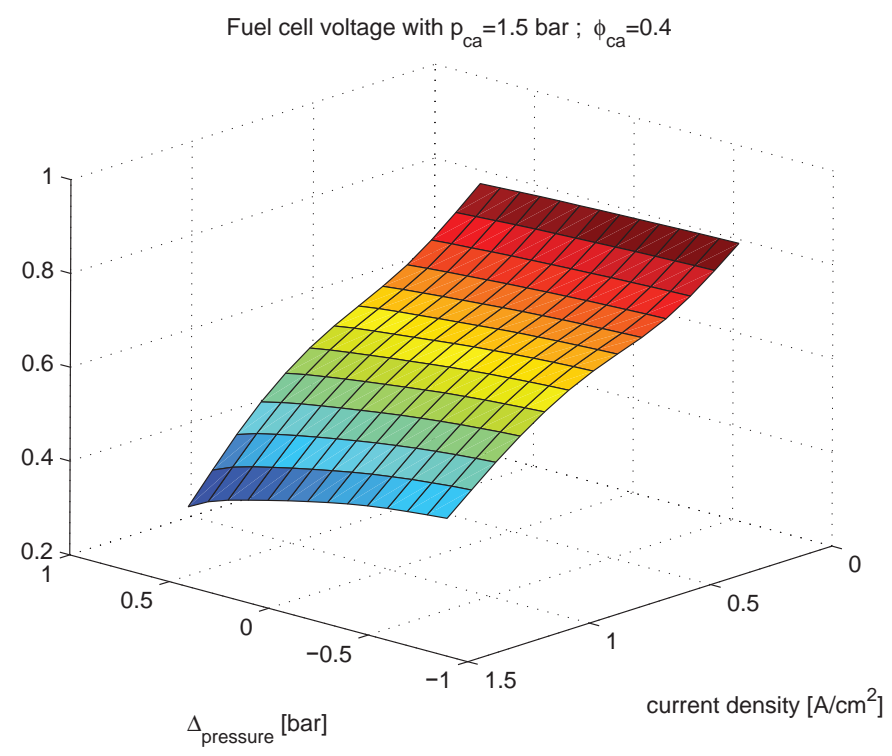

Fig. 3. Cell voltage as a function of current density and pressure difference at constant cathode pressure and relative humidity. 


\begin{tabular}{|l|c|}
\hline Variables & Values \\
\hline Active cell area $\left[\mathrm{cm}^{2}\right]$ & 312 \\
\hline Membrane thickness $[\mu \mathrm{m}]$ & 51 \\
\hline Number of cells & 385 \\
\hline Desired cathode relative humidity & 0.6 \\
\hline Inlet anode relative humidity & 0 \\
\hline Max current demand & 230 \\
\hline Fuel cell temperature $[\mathrm{K}]$ & 353 \\
\hline Fuel utilization & 0.9 \\
\hline Excess of air & 2 \\
\hline
\end{tabular}

Table 4. Fuel cell parameters.

valves on both sides and the compressor command. Figure 4 shows open-loop results under three different loads (see Figure 4(a)).

From the open-loop results, it is worth noting that both electrode pressures increase when the current demand approaches higher value, thus ensuring a higher mass flow rate as expected. In particular, note that oxygen mass guarantees the electrochemical reaction for each value of current demand chosen, avoiding stack starvation. Moreover, because the compressor increases its speed, a fast second order dynamic results in the air mass flow rate delivered, whereas a slower first order dynamic corresponds to the electrodes pressures. These results indicate that the model captures the critical dynamics, producing results as expected.

\subsection{Control strategy and reference inputs}

Because the fuel cell system must satisfy the power demand, oxygen starvation is an issue and must be avoided. In fact, the air mass flow rate decreases for each load change and the control system must avoid fast cell starvation during the transient. Thus, increasing power requirements lead to higher mass flow rates fed by the compressor and higher pressures in the volumes. Moreover, Figure 5 indicates that as long as pressurized gases are supplied, the fuel cell improves its performance, providing higher voltage at high current density, without reaching the region of high concentration losses.

Pressurized gases increase cell efficiency, but since the stack experiences a nontrivial energy consumption to drive the motor of the compressor, the overall system efficiency drops, described by

$$
\eta_{s y s}=\frac{P_{s t}-P_{c m p}}{W_{i n, H_{2}} L H V_{H_{2}}}
$$

where $P_{s t}$ is the electrical power generated by the stack, $P_{c m p}$ is the power absorbed by the compressor, $W_{i n, H_{2}}$ is the amount of hydrogen provided and $L H V_{H_{2}}$ is lower heating value for the fuel. In order to achieve the best system efficiency, the entire operating range in terms of requested power and air pressure is investigated. Using a simple optimization tool, for each value of current demand a unique value of optimal pressure can be derived, maximizing the system efficiency. Thus, the map showed in Figure 6 interpolates the results of the optimization and plots the optimal pressures as functions of the desired current. Furthermore, since the membrane should not experience a significant pressure difference between the electrodes, the pressure set points related to the anode side have been chosen to have values of 0.1 bar lower than the optimal cathode pressure. 

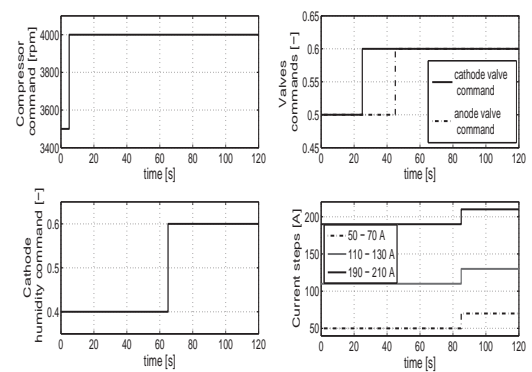

(a) Step inputs

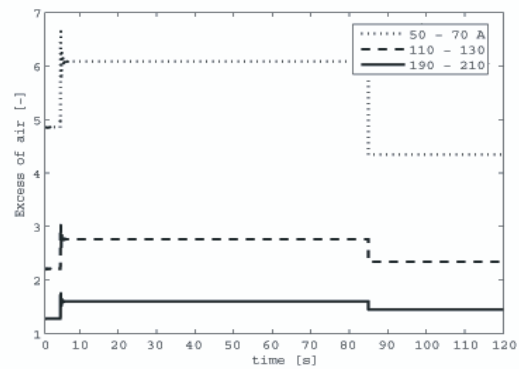

(c) Excess of air

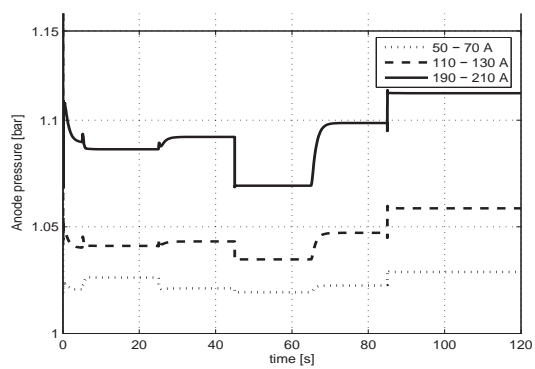

(e) Anode pressure

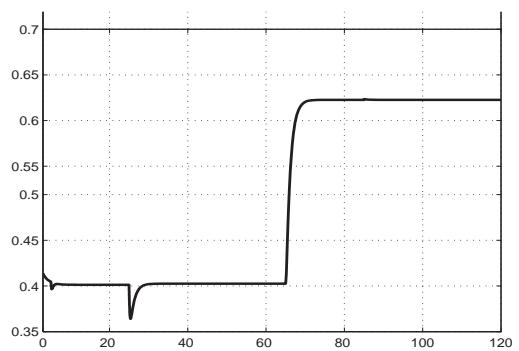

(g) Cathode relative humidity

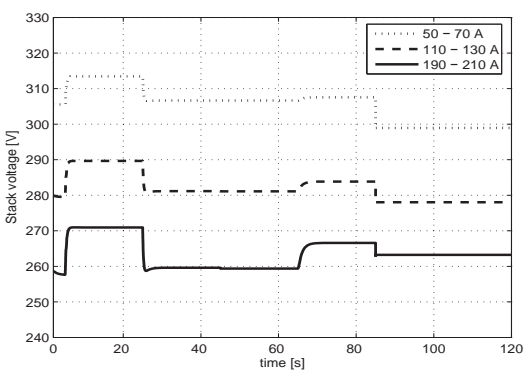

(b) Stack voltage

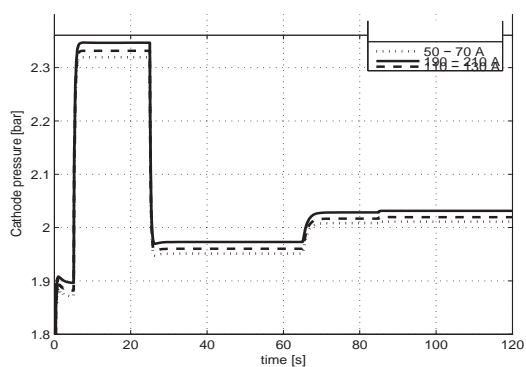

(d) Cathode pressure

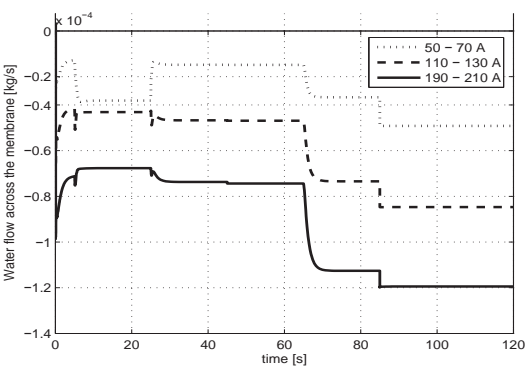

(f) Membrane water flow

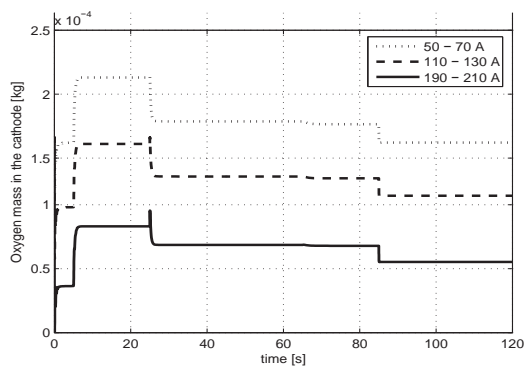

(h) Cathode oxygen mass

Fig. 4. Results for the open loop model. 


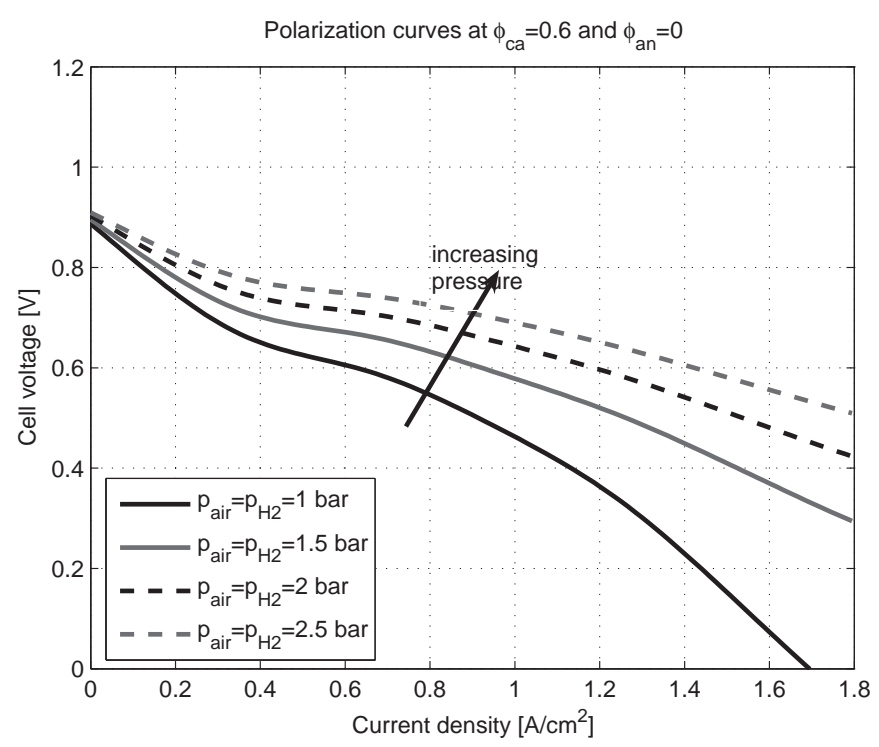

Fig. 5. Fuel cell polarization curves for different pressures.

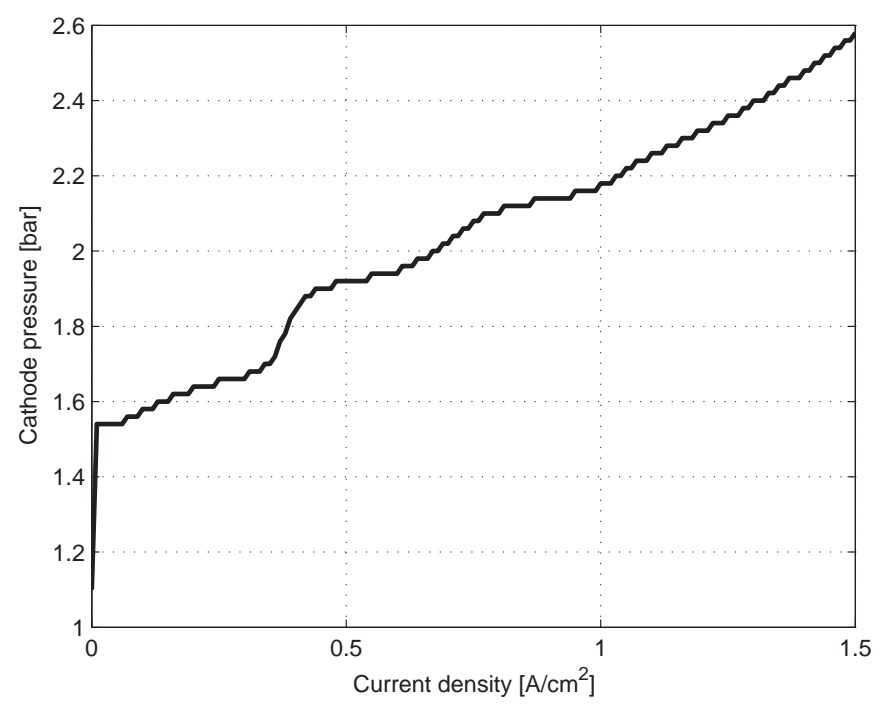

Fig. 6. Cathode optimal pressure as function of the current demand. 
The current demand translates into a requested air mass flow rate, choosing the excess air equal to 2, i.e. air flow twice the required by stoichiometry (Bansal et al., 2004):

$$
W_{c p, r e q}=\frac{I_{s t} M_{\mathrm{O}_{2}} \lambda_{\text {des }} N}{4 F 0.233}
$$

where $\lambda_{\text {des }}$ is the excess of air ratio. The low level control showed must operate the fuel cell stack at his best efficiency point while meeting the demanded current.

\subsection{Feed-forward component}

The main advantage of using a feed-forward control component is to obtain an immediate effect on the system response. Since there are three different actuators in this system, three static maps have been built. A 2-D map was built for the compressor speed based on the air flow and the cathode pressure. The anode and cathode back-pressure valves have been adjusted by two different static maps based on the optimal pressure for each volume.

Figure 7 shows that simple feed-forward control alone is not adequate to achieve a fast and accurate response; the plots are for various quantities of interest for the feed-forward control alone applied to the full nonlinear truth model. Being essentially an open-loop action, the feed-forward control is certainly not robust during transient operation, because it is obtained based on steady state responses of the available model. Consequently, there is a need for a more complicated system control that can produce a faster response with less steady state error, and one that is robust to modeling uncertainties, sensor noise, and variations.

\section{Linear control}

\subsection{Model reduction and linearization}

Linearization of the complex nonlinear truth model requires specification of an operating point, obtained here as open loop steady-state response with the nominal values given in Table 5. This nominal operating point represents a reasonable region of operation where all parameters are physically realizable.

Since the compressor airflow and pressure in the cathode return manifold affect the power produced, they are chosen to be the system outputs. Moreover, these variables are available and easy to measure in an actual application. Their values, corresponding to the operating condition in Table 5, are $0.023 \mathrm{~kg} / \mathrm{sec}$ and 1.7 bar for the compressor air flow and return manifold cathode pressure, respectively.

For the purpose of specifying the control inputs, the inlet humidity level is considered constant at 0.6. From the physical fuel cell system configuration, the anode control valve is virtually decoupled from the cathode side of the fuel cell system, and the same static feedforward map used in the feedforward scheme is used here to control the anode control valve (Domenico et al., 2006). Therefore, the two control inputs are chosen to be the compressor speed command and the cathode return manifold valve command. The linearization therefore produces a control-oriented model with two inputs and two outputs.

\begin{tabular}{|c|c|}
\hline Variable & Operating point \\
\hline Current & $80 \mathrm{~A}$ \\
\hline Compressor speed command & $2800 \mathrm{RPM}$ \\
\hline Cathode valve opening & $38 \%$ \\
\hline Anode valve opening & $48 \%$ \\
\hline Humidity & $60 \%$ \\
\hline
\end{tabular}

Table 5. Operating values for linearization. 


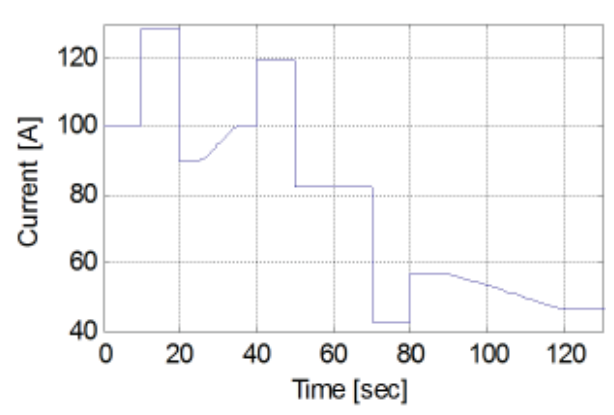

(a) Current trajectory

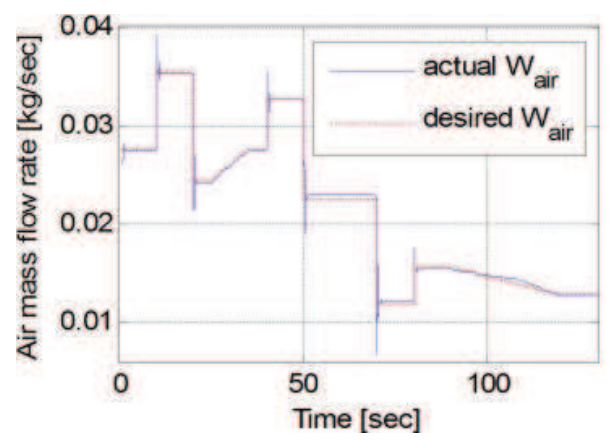

(c) Air mass flow rate

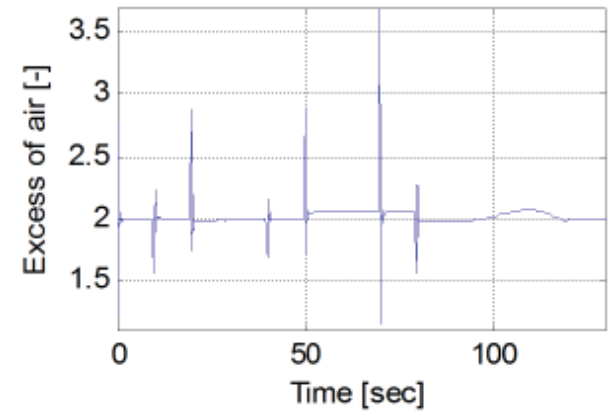

(b) Excess of air

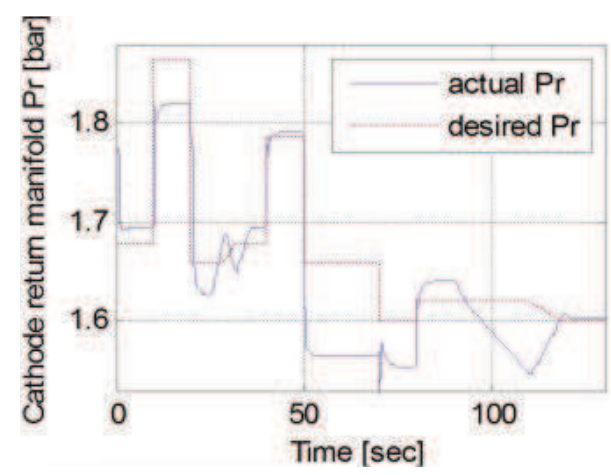

(d) Cathode pressure

Fig. 7. Response for feed-forward control, applied to nonlinear truth model.

The time-based linearization block in Simulink is used to linearize the model using the LINMOD command over a specific simulation time interval (Domenico et al., 2006). The resulting continuous-time linearized model is given in standard state-variable form as

$$
\begin{aligned}
& \dot{x}=A x+B u \\
& y=C x+D u
\end{aligned}
$$

where $x$ is the state vector, $y$ is the system output, $u$ is the system input, and $A, B, C$, and $D$ are matrices of appropriate dimension.

The 13-state linear system obtained in this way is highly ill-conditioned. To mitigate this problem, a reduced-order 5-state model is derived by returning to the nonlinear simulation and reducing the order of the nonlinear model. Based on the frequency range most important to and most prominently affected by the system controller, namely, for the compressor and the back pressure valve, some states are targeted for removal in model-order reduction. That is, the states associated with the cathode and anode (states 1-5 and 9-11 in Table 3) possess much faster dynamics relative to the other five states. Therefore, static relationships to describe those states are represented in the form of simple algebraic equations. This results in a 5-state reduced order model that preserves the main structural modes that we wish to control (Domenico et al., 2006). The remaining states for the 5th order model are: i) Vapor pressure cathode SM; ii) Dry air pressure cathode SM; iii) Air pressure cathode RM; iv) Compressor 


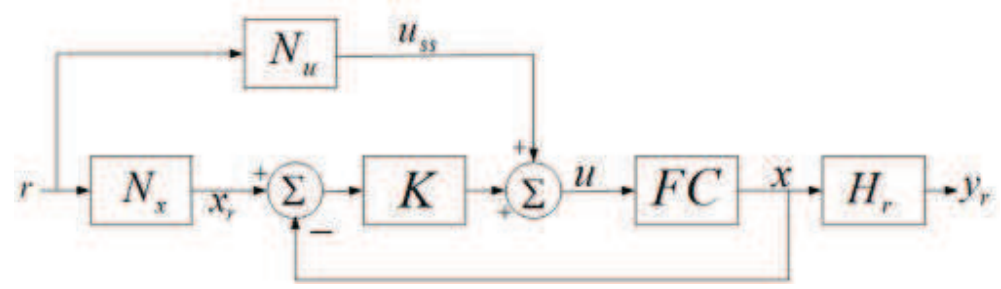

Fig. 8. State command structure.

acceleration; v) Compressor speed, where SM refers to supply manifold and RM refers to return manifold.

The analysis of the full nonlinear model, and subsequent linearization (with validation) for this system were reported in (Domenico et al., 2006). Analysis of the resulting linear models reveals that the 13-state model is stable and controllable, but not completely observable; however, the unobservable state is asymptotically stable. The reduced-order 5-state model is stable, controllable and observable.

\subsection{Control design}

\subsubsection{The state-command structure}

The linear control scheme chosen for this application is full state feedback for tracking control with a feed-forward steady-state correction term. For the feed-forward part, a state command structure is used to produce the desired reference states from the reference input tracking command. A steady-state correction term, also a function of the reference, augments the control input computed from the state feedback (Franklin et al., 1990). The controlled-system configuration is depicted as the block diagram in Figure 8.

The control scheme consists of two main parts: the feed-forward and the state feedback control. For the feedback part, a state command matrix $N_{x}$ is used to calculate the desired values of the states $x_{r} . N_{x}$ should take the reference input $r$ and produce reference states $x_{r}$. We want the desired output $y_{r}$ to be at the desired reference value, where $H_{r}$ determines the quantities we wish to track. Also, the proportionality constant $N_{u}$ is used to incorporate the steady state, feedforward portion of the control input $\left(u_{s s}\right)$. Calculation of $N_{x}$ and $N_{u}$ is a straightforward exercise; the task remaining is to specify the matrix $K$, which is the subject of the next section.

For our structure, the controller objective is to track the optimum compressor supply air flow $\left(r_{1}\right)$ and the optimum cathode return manifold pressure $\left(r_{2}\right)$. We will assume that the compressor supply air flow and the cathode return manifold pressure are measured and are outputs of the system $\left(y_{r}\right)$. The plant input vector consists of the compressor speed and the cathode return manifold valve opening $(u)$. Clearly, the system will be a multi-input, multi-output system (MIMO).

\subsubsection{LQR design}

Because there are many feasible configurations for the state feedback gain matrix, the method we will use herein is the Linear Quadratic Regulator (LQR) control method which aims at realizing desirable plant response while using minimal control effort. The well-known objective of the LQR method is to find a control law of the form that minimizes a performance index of the general form 


$$
J=\int_{0}^{\infty}\left(x^{T} Q x+u^{T} R u\right) d t
$$

For ease in design, we choose diagonal structures for the $Q$ and $R$ matrices in (14), with elements based on simple rules of thumb: (i) the bandwidth of the system increases as the values of the $Q$ elements increases (Franklin et al., 1990); (ii) some system modes can be made faster by increasing the corresponding elements in the $Q$ matrix; (iii) input weights in the $R$ matrix can be used to force the inputs to stay within limits of control authority. In addition to these rules, intuition about the system is needed to be able to specify the $Q$ and $R$ matrices. In our model, we know from the eigenvalues that the second and third states are the slowest, so we can put high penalty on the corresponding $Q$ elements in order to force the state to converge to zero faster. Also, for design of the $R$ matrix, it is important to maintain the valve input to be within $[0-1]$. That is, the corresponding element in $R$ should be chosen so as to force the input to stay within this range. Otherwise, if for example the control signal were truncated, saturation incorporated into the nonlinear system model would truncate the control signal provided by the valve input, which could ultimately result in instability.

\subsubsection{Simulation results}

The full nonlinear truth model is used in all control result simulations to follow. The LQR controller described above is implemented based on the structure depicted in Figure 8, assuming full state feedback. Figure 9 shows the various responses obtained from application to the full nonlinear simulation, for a trajectory current input consisting of a sequence of steps and ramps emulating a typical user demand in the vehicle.

The response is adequate, especially in a neighborhood of the nominal point (current demand $I=80 A$ ). However, if the input demand goes over $130 \mathrm{~A}$, assumptions of linearity are violated, and the responses diverge. Thus, to illustrate these results we use a trajectory which keeps the system in a reasonable operating range.

For these results, the air excess ratio is almost at the desired value of 2 when the system stays close to the nominal point. But that value increases rapidly if the demand goes higher, which will lower the efficiency of the system (supplying more air than the FC needs). For the air mass flow rate and the cathode return manifold pressure responses, we obtain a good response in the vicinity of the linearization region $(0.023 \mathrm{~kg} / \mathrm{sec}$ and 1.697 bar for the compressor air flow rate and the cathode return manifold pressure, respectively). Even though these results are adequate for operation within the neighborhood of the nominal point of linearization, we have assumed that all states are available for feedback. In reality, we would not have sensors to measure all five states. Therefore, we move to schemes wherein the control uses feedback from measurable outputs.

\subsection{Observer-Based Linear Control Design}

The control law designed in section 3.2 assumed that all needed states are available for feedback. However, it is typically the case that in practice, the various pressures within the fuel cell system are not all measured. Therefore, state estimation is necessary to reconstruct the missing states using only the available measurements.

For the system of this study, an observer is designed for the reduced-order (5-state) model, where the available measurements are taken to be the system outputs: compressor airflow rate and cathode return manifold pressure. The observer is designed to produce the estimated state, $\hat{x}$, according to 


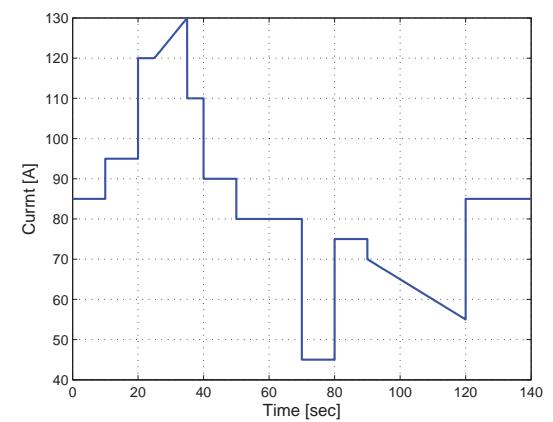

(a) Current trajectory

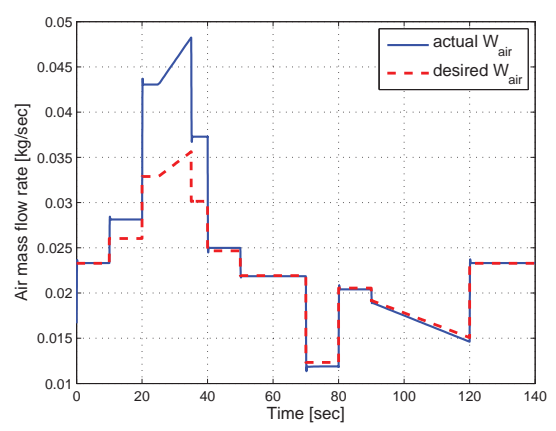

(c) Air mass flow rate

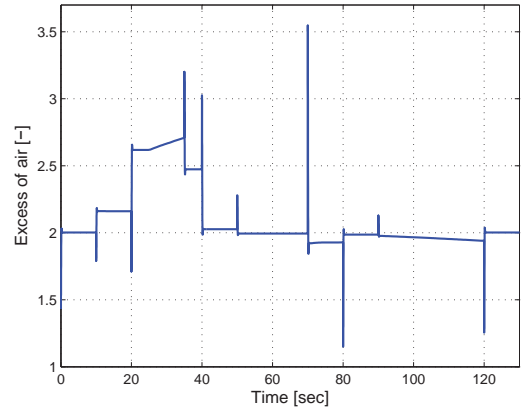

(b) Excess of air

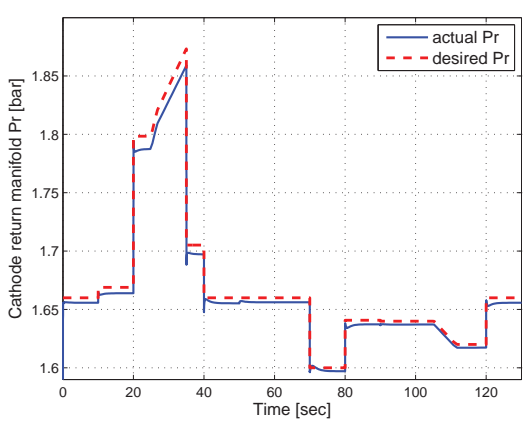

(d) Cathode pressure

Fig. 9. Response using full-state feedback, applied to nonlinear truth model.

$$
\begin{aligned}
& \dot{\hat{x}}=A \hat{x}+B u+L(y-\hat{y}) \\
& \hat{y}=C \hat{x}+D u
\end{aligned}
$$

where, $L$ is the observer gain matrix, and $\hat{x}$ and $\hat{y}$ represent the estimated state and output, respectively. The observer-based control design structure is depicted by the block diagram in Figure 10. In this design, the observer poles are placed so as to achieve a response which is three times faster than the closed-loop response (determined by the control poles), guaranteeing that the estimated states converge sufficiently fast (to their true values) for this application.

Almost the same current input demand used for the responses in Figure 9(a) is used in this simulation, except that we shortened the range of operation because of unstable behavior outside this range. Figure 11 shows that the air mass flow rate and the cathode return manifold pressure responses are very good except when we deviate from the nominal point of linearization (very clear from the peak at $t=35 \mathrm{sec}$ ). Nonetheless, their responses are very quick and accurate in a small neighborhood of the nominal point. The air excess ratio is almost at the desired value of 2, except during the transients.

Compared to the feedforward response alone, these results are an improvement when the system operates close to the nominal point at which we linearized the system. The more the 


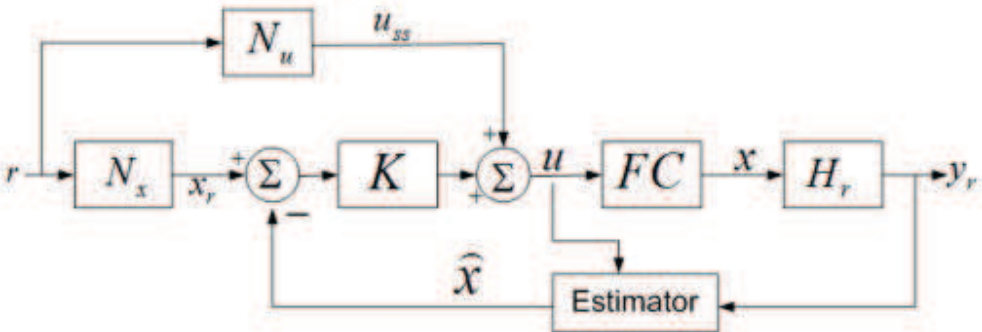

Fig. 10. Control structure with observer.

system deviated from this point, the worse the response was. In fact, if we demanded more than $95 A$, the response diverged. To overcome this problem, we move to the next phase of this study, which is to investigate a more sophisticated control technique that will allow a wider range of operation.

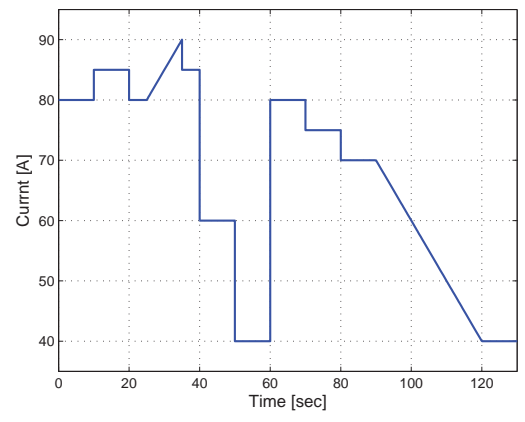

(a) Current trajectory

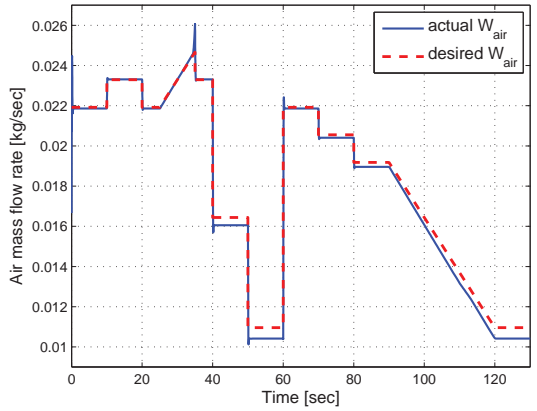

(c) Air mass flow rate

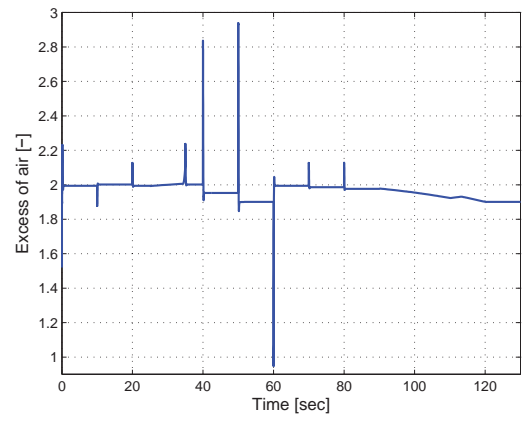

(b) Excess of air

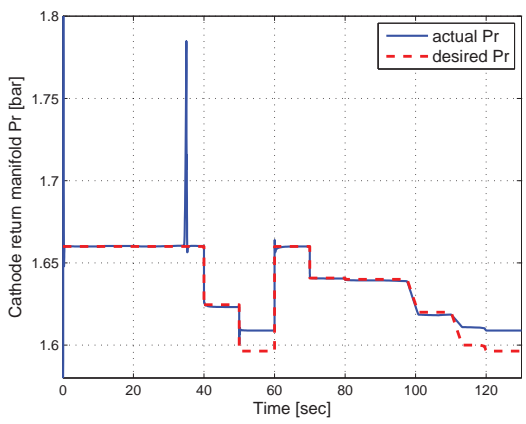

(d) Cathode pressure

Fig. 11. Response to observer-based feedback, applied to nonlinear truth model. 


\section{Gain scheduled control}

In this section we investigate a nonlinear control approach, referred to as gain scheduling. The basic idea behind gain-scheduled control is to choose various desired operating points, model the system at these points, and apply an appropriate controller (in this case, linear) for each of these ranges.

Gain scheduling is a common engineering practice used to control nonlinear systems in many engineering applications, such as flight control and process control (Shamma \& Athans, 1992). The main idea is that one algorithm from several different control designs is chosen based on some operating conditions. The control algorithms are designed off-line with a priori information, so the main job of gain scheduling is to identify the proper control algorithm to be used. Herein, the design is broken into exclusive regions of operation. In each region, a fixed control design is applied about a nominal point that is included in that region. Then, a global nonlinear control is obtained by scheduling the gains of the local operating point designs. The controller parameter that determines selection of the appropriate operating region is called the scheduling variable.

Despite the popularity of gain scheduling techniques, they are sometimes considered in a class of ad hoc methodologies, since the robustness, performance, or even stability properties of the overall design are not explicitly addressed (Shamma \& Athans, 1992). However, we can infer these properties via extensive simulations. Many heuristic rules-of-thumb have emerged in guiding successful gain scheduled design; however, the most important guideline is to ensure "slow" variation in the scheduling variable. In (Shamma \& Athans, 1992), "slow" is defined for situations wherein the scheduling variable changes slower than the slowest time constant of the closed loop system.

\subsection{Scheduling regions}

The electrical current demand is chosen to be the scheduling variable that determines the instantaneous operating region. With each different current demand level, the desired reference inputs are picked from the feedforward open-loop system given earlier. To cover the region from $I=0 A$ to $I=150 A$, the domain is divided into six exclusive regions as shown in Table 6.

The criteria for choosing these regions is ad hoc in nature, and based on the results obtained in the last section. We noticed from the linear control results that the low current demand (below $50 \mathrm{~A}$ ) has less-pronounced nonlinear behavior, so the first region covers the larger domain (see Table 6). The rationale for making the range of the other domains of length $20 \mathrm{~A}$ is the rapidly unstable behavior noticed when the demand exceeded $90 \mathrm{~A}$, while the nominal point was 80A. To proceed with the gain scheduled implementation, the 5-state nonlinear fuel cell model is linearized at each of the operating points specified in Table 6. Thus, we obtain six different state matrices, one for each operating point. Then, six linear controllers are designed offline,

\begin{tabular}{|c|c|c|c|c|c|c|}
\hline Region & $I$ & $I I$ & $I I I$ & $I V$ & $V$ & $V I$ \\
\hline $\begin{array}{c}\text { Range of current } \\
\text { demanded [A] }\end{array}$ & {$[0,50)$} & {$[50,70)$} & {$[70,90)$} & {$[90,110)$} & {$[110,130)$} & {$[130,150]$} \\
\hline Nominal current [A] & 40 & 60 & 80 & 100 & 120 & 140 \\
\hline $\begin{array}{c}\text { Compressor } \\
\text { airflow rate [g/s] }\end{array}$ & 11.4 & 16.2 & 22.9 & 27.3 & 32.9 & 38.4 \\
\hline $\begin{array}{c}\text { Cathode return } \\
\text { manifold pressure [bar] }\end{array}$ & 1.53 & 1.67 & 1.70 & 1.77 & 1.80 & 1.89 \\
\hline
\end{tabular}

Table 6. Operating regions based on the current demand level. 


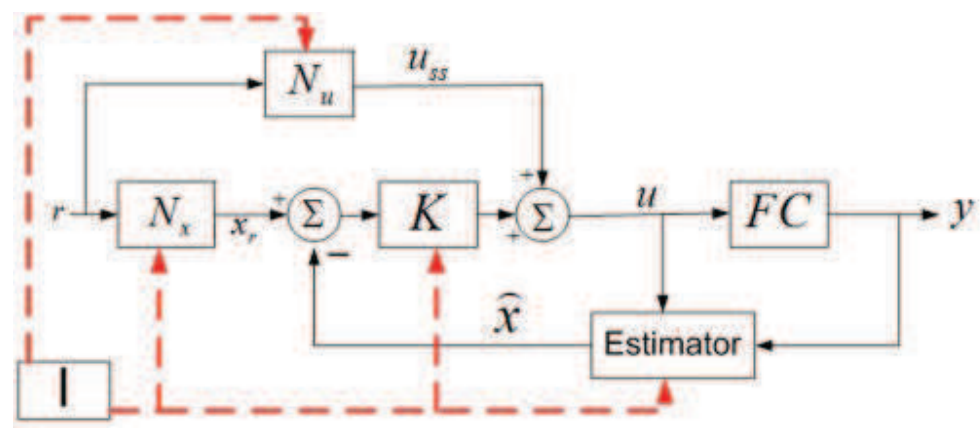

Fig. 12. Gain scheduling scheme.

based on each linearized model. Consequently, we obtain six matrices for each control matrix $\left(N_{x}, N_{u}\right.$, and $\left.K\right)$ as well as six observer gain matrices $(L)$. The diagram in Figure 12 is similar to that of Figure 10, but is adapted to the gain scheduling scheme.

Figure 13 gives the response of the gain-scheduled control with a current demand input similar to that in Section 3, but with wider range. The air mass flow rate and the cathode return manifold pressure responses are very good, except for a few jumps and very small steady state errors (under $1 \%$ in either case). However, the overshoot of the cathode return manifold pressure at $t=35$ seconds almost reaches $10 \%$, which in theory is undesirable (but in practice may not actually be realized). The air excess ratio is very near the desired value of 2 , except for the drop at $t=120$ seconds, which is due to operation away from the nominal value of region-I.

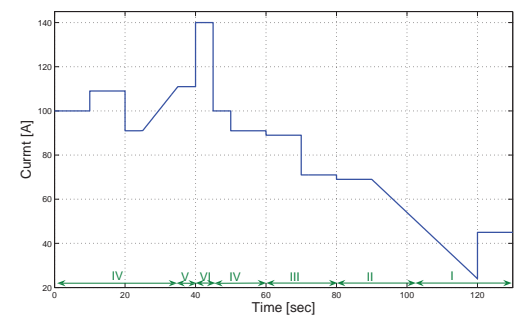

(a) Current trajectory

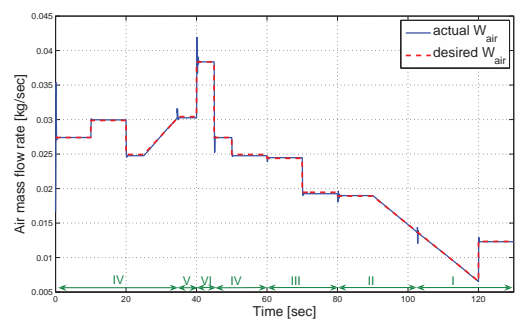

(c) Air mass flow rate

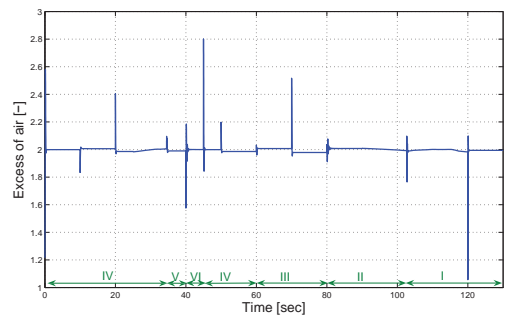

(b) Excess of air

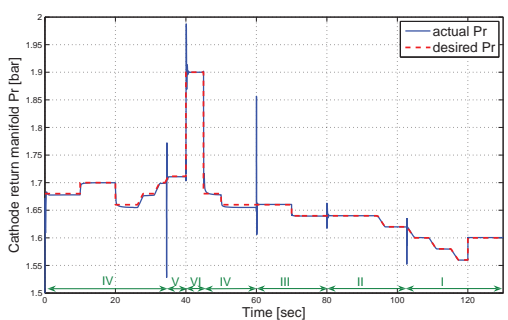

(d) Cathode pressure

Fig. 13. Response for Gain-Scheduled Control, Applied to Nonlinear Truth Model. 


\subsection{Controller refinement}

The results of the gain scheduling controller are quite good, except during the transients; this behavior is characteristic of this type of control scheme. That is, the most important design constraint for gain scheduling is the requirement for slow variation of the scheduling variable. The input current trajectory that we are using has very fast frequency components because of the nature of the steps (in actual implementation, however, such harsh steps can often be avoided by appropriate input shaping). This fast switching causes a rapid change in the controller as well as the observer gains, which results in the spike behavior. This is true even for some steps of smaller amplitude, such as in the cases for $t=60$ seconds or $t=80$ seconds; in those cases, the system "quickly" switches across regions. To mitigate the effects of fast switching in the gains, we will introduce a technique combining two components: (i) interpolation of the gain matrices, and (ii) shaping the current input trajectory.

\subsubsection{Interpolating the gain matrices}

In this method, some of the gain matrices are interpolated with respect to the gain scheduling variable. Interpolation of state feedback and observer gains is used to obtain a smooth transition from one region to another (Rugh \& Shamma, 2000). There are many different methods of interpolation; however, the simplest method is linear interpolation.

Recall that we have six matrices (one for each region) of each type of the gain matrices (K, $N_{x}, N_{u}$, and $L$ ) resulting from the observer-based control design that can be interpolated as depicted in Figure 14 to render the six sets of matrices into one sit for the overall range. The elements of each of the resulting matrices, for example $\overline{\mathbf{K}}$, are a function of the scheduling variable (current demand). As the current demand trajectory changes, the gain matrices change more smoothly, as compared to fast switching used in the previous subsection. An interpolation of $K, N_{x}$, and $L$, but not $N_{u}$, provided the best results (Al-Durra et al., 2007), and are used in conjunction with the second component, input shaping.

\subsubsection{Input shaping}

The idea of input shaping has shown an advantage in reducing vibration and subsequent excitations caused by rapid changes in reference command (Fortgang \& Singhose, 2002), (Tzes \& Yurkovich, 1993). As mentioned earlier, to have an effective gain scheduled controller, the scheduling variable should not change faster than the slowest dynamic in the system. This restriction was violated in the control results given to this point, since the scheduling variable (current input trajectory) is characterized by step functions. We now investigate the concept of shaping the current trajectory by passing it through a low pass filter. However, since we still want to see the response to fast transients, we design the corner frequency of the filter to be at $10 \mathrm{~Hz}$; this choice is relatively fast by drivability standards, and would not noticeably change vehicle responsiveness.

Figure 15 shows the results achieved by refining the gain-scheduled control using input shaping with the interpolated gain concept of the last section. Comparing the results of Figure 13 and Figure 15 and using the same current input as in 13(a), we see improvement in the excess of air ratio, now between 1.75 and 2.2, compared to 1.5 and 2.8 without the refinement. Overall, we notice fewer variations, but the response still suffers from the transients (spikes).

\section{Rule-based control}

Controlling a nonlinear system using a sophisticated nonlinear control technique, such as feedback linearization or sliding mode control, requires knowledge of the nonlinear 


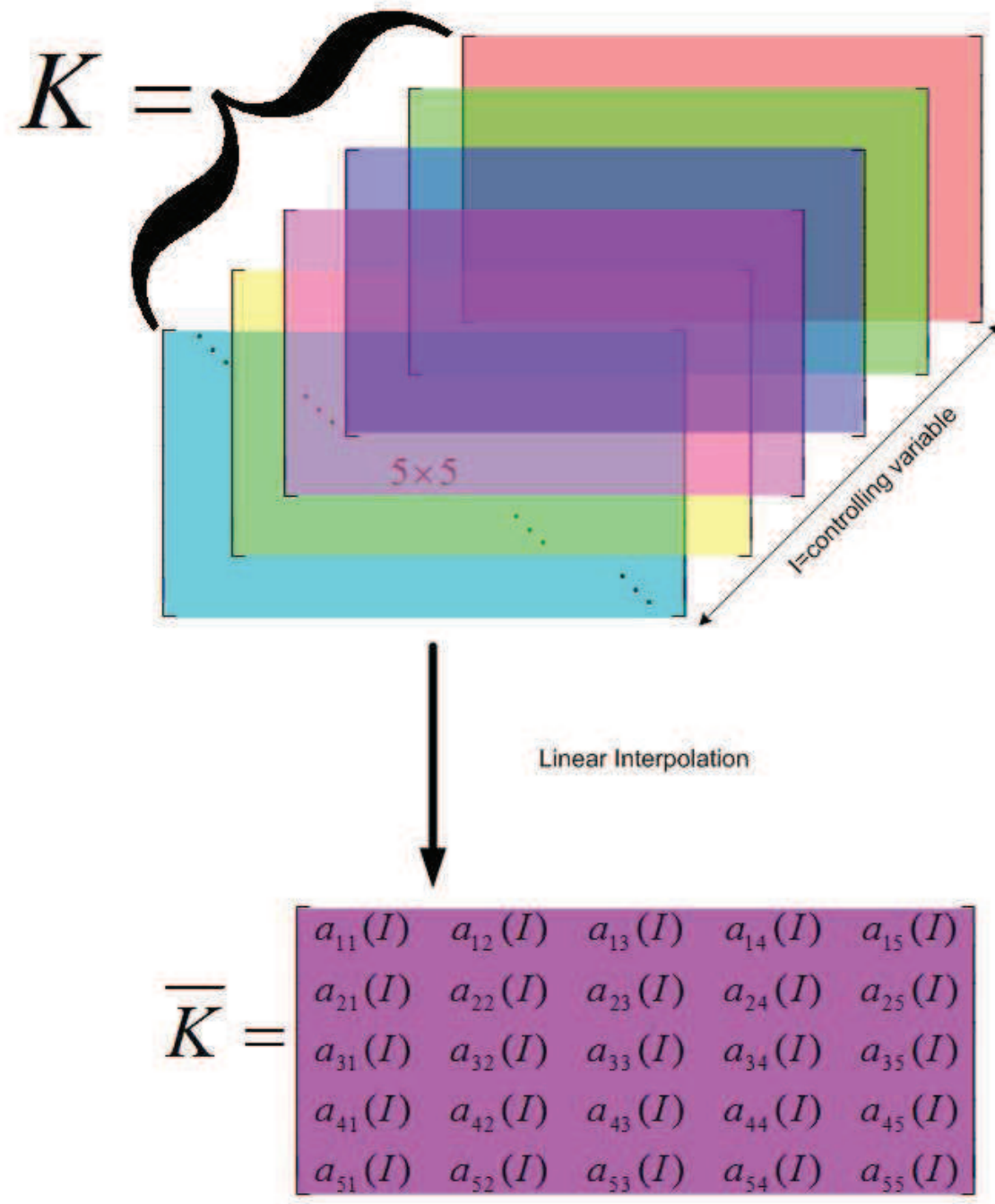

Fig. 14. Linear interpolation. 


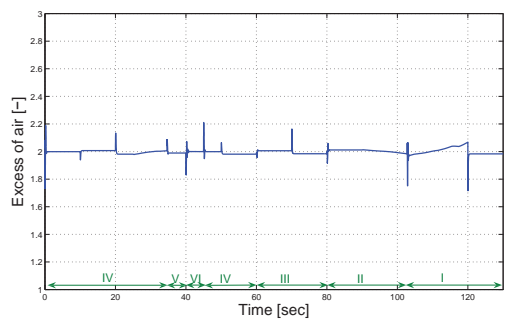

(a) Excess of air

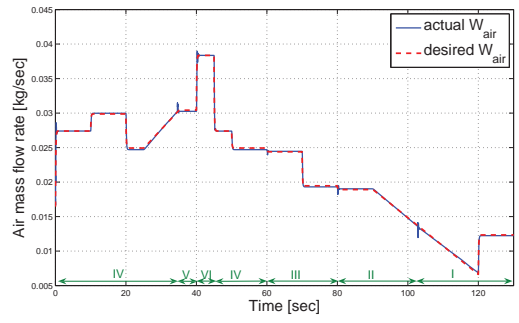

(b) Air mass flow rate

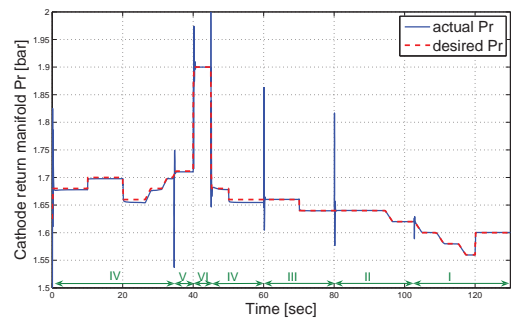

(c) Cathode pressure

Fig. 15. Gain scheduling using interpolation and input shaping, applied to nonlinear truth model.

differential equations describing the system. Our PEM fuel cell model contains several maps and lookup tables which limit our ability to use such model-based nonlinear control. Linearization of the system and application of linear control gave an adequate response only in the vicinity of the point of linearization. Expansion to a gain-scheduled control widened the range of operation, but the response still suffered somewhat from transient spikes when switching from one operating region to another. In this section, another nonlinear control technique is explored, rule-based control, which does not require full knowledge of the dynamical equations of the system. The results and experience gained in the control schemes of the preceding sections are used here for synthesis of the controller.

\subsection{Rule-based control implementation on the PEM-FC model}

A rule-based controller can be characterized as an expert system which employs experience and knowledge to arrive at heuristic decisions. Most often, the design process is a result of experience with system operation (Passino \& Yurkovich, 1998).

\subsubsection{Choosing the rule-based controller inputs and outputs}

The input to the controller should be rich enough to lead to decisions that produce the system input (output of the controller); those decisions are based on the knowledge base made up of cause and effect rules. In order to ascertain which signals are relevant as controller inputs, we study the coupling between the inputs and the outputs of the PEM-FC model, and control results from the previous sections. From the linearized models obtained in various regions, frequency response information (Bode plots) can be utilized. For example, this characterization for region-III shows that the gain from input- 1 to output- 2 is at most $-70 \mathrm{~dB}$, 
indicating mild coupling. The same results appeared for the correlation between input-2 and output- 1 where the gain is at most $-125 \mathrm{~dB}$. From this we conclude that we can regulate the system inputs using a single-input, single-output approach for two separate subsystems (air and pressure), neglecting the mild coupling.

\subsubsection{Rule-based controller characteristics}

In this design, a typical fuzzy control scheme (Passino \& Yurkovich, 1998) is used. The number of triangular membership functions for each controller input and output is nine; a higher number could lead to greater precision, but at the expense of increased computations. The shape of each membership function is chosen to be triangular, since this will reduce the computations needed (compared to, for example, Gaussian-shaped membership functions). A typical process in design is to shift the centers of these functions, to be closer to or further away from the origin on the input scale, in order to result in a certain effect. For example, if shifted closer to the origin, the intent is to stress the effect of that particular membership function for smaller values of the input, and vice versa. It should also be noted that separations between the membership functions were tuned empirically, based on prior experience in such designs. However, the general trend for the separation is linear; that is, the positions are closer for the memberships close to the origin and the separation is wider for those away from the origin.

Another important characteristic in the design of rule-based controllers is the domains (universes of discourse) of each controller input and output. For this problem, these are chosen based on the experiences reaped from the gain-scheduled control design described earlier, indicating the range of values for the controller input and output shown in Table 7. For the inference operation, the min function (truncation) is chosen it requires fewer calculations when compared to the prod (scaling) function; the max operation is used for aggregation. Finally, to produce a crisp controller output (the defuzzification step), the centroid method is used.

\subsection{Control design and simulation}

Because there are few systematic design methods for constructing a rule-based control system, several control schemes were investigated in this work. Two schemes are compared in this section.

\subsubsection{Baseline design}

The controller inputs $\left(v_{i}\right)$ for each separate controller (air and pressure) are the error between the reference inputs $\left(r_{i}\right)$ and the system outputs $\left(y_{i}\right)$. However, to avoid transient spikes in the control inputs to the system, a concept of "memory" in the control will be needed to remember the previous error received. Therefore, integrators are added, limited to avoid exceeding each controller authority; the resulting lag introduced into the system response can be mitigated by adding a gain to the output of the rule-based controller. Figure 16(a) shows the Baseline control scheme with integrators and gains; by increasing the gains $\left(g_{i}\right)$, the system response time can be decreased in a tradeoff with other characteristics (such as overshoot and settling

\begin{tabular}{|c|c|}
\hline Input $(v) /$ Output $(u)$ & Universe of Discourse \\
\hline$v_{1}$ & {$[-0.03,0.03]$} \\
\hline$u_{1}$ & {$[-3000,3000]$} \\
\hline$v_{2}$ & {$[-4,4]$} \\
\hline$u_{2}$ & {$[-1,1]$} \\
\hline
\end{tabular}

Table 7. Domains for controller inputs and outputs. 


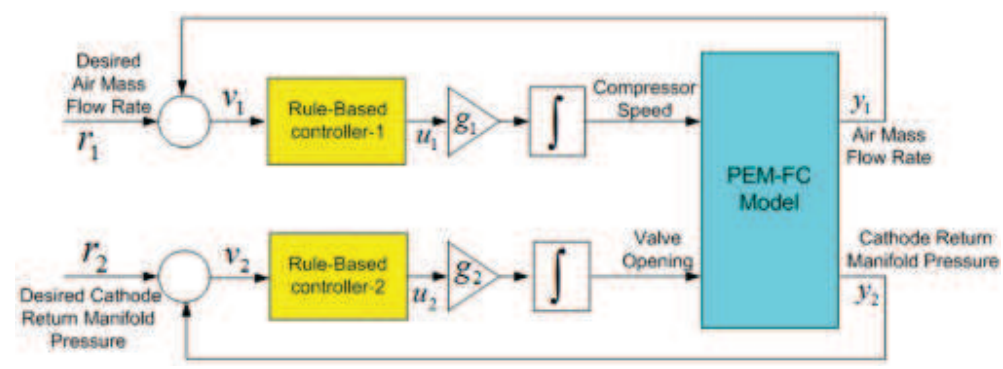

(a) Baseline rule-based control system

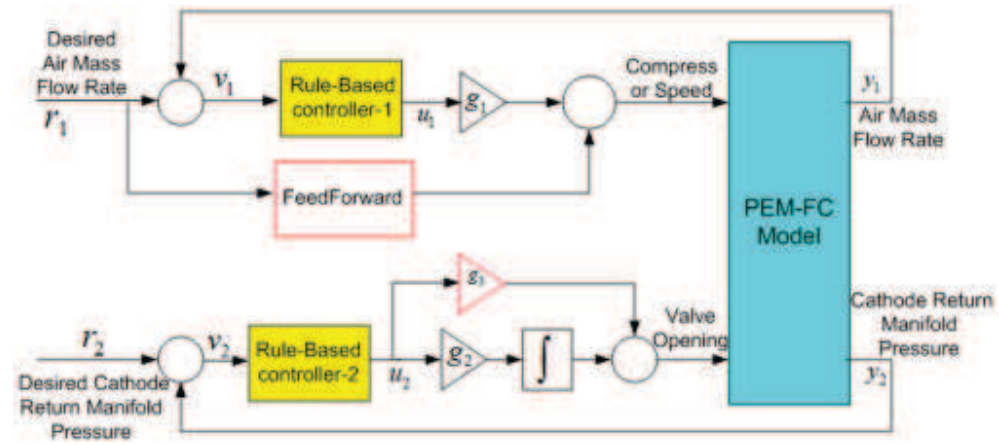

(b) Baseline rule-based control with feedforward component.

Fig. 16. Rule-based schemes.

time). The fuzzy surfaces that characterize each of the two controllers (controller input-output maps) behave similarly to an inverse tangent curve, designed in order to diminish the effect of rapid changes in the errors $\left(v_{i}\right)$ to avoid the transient spike effects seen with the gain scheduled controller.

The response of this Baseline scheme, for the same current trajectory (Figure 13(a)), is shown in Figure 17 (a,b, and c). Compared to the results of the gain scheduled control, the air mass flow rate has improved (less transient effect with less steady state errors). However, lag is noticeable in the response due to the integrator; note, for example, in the transient at $t=40$ seconds, more than a half second is needed to reach a 5\% settling time. The cathode return manifold pressure responses improve, but still suffer from transient spikes. The air excess ratio is now almost at 2 most of the time; however, spikes are still noticeable, particularly at $t=120$ seconds, which could damage the fuel cell.

\subsubsection{Addition of feedforward component}

The two deficiencies of the Baseline design can be remedied with simple feedforward components. The first deficiency is the slow response of the compressor air mass flow rate. This can be improved by adding a nonlinear feedforward term that is based on the steady state plant inverse response. In so doing, we remove the first integrator to further increase the speed of the response. The second deficiency of the Baseline controller is presence of transient spikes in the cathode return manifold pressure. Decreasing the gain of the integrator has a positive effect, but a proportional gain is needed to obtain a faster response. Figure 16(b) 


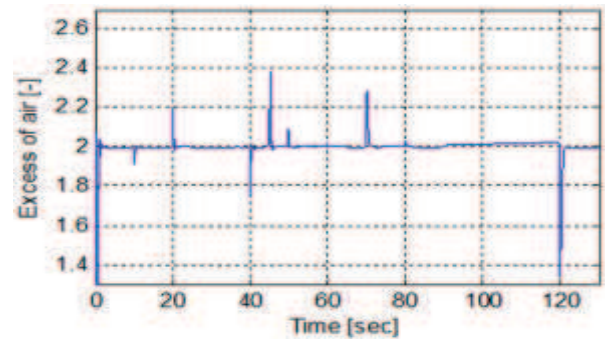

(a) Excess of air

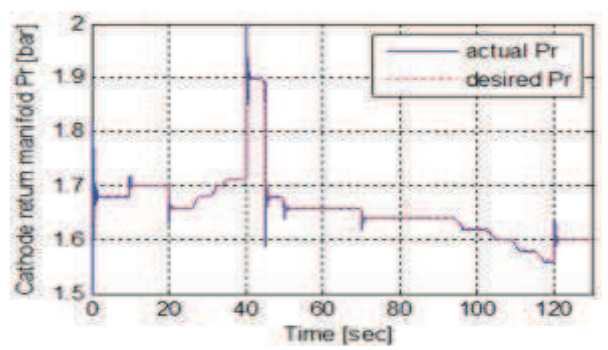

(c) Cathode pressure

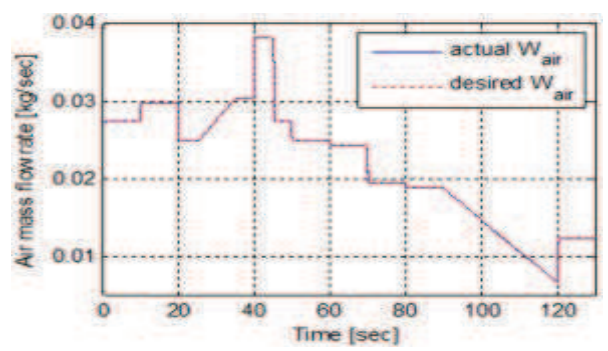

(e) Air mass flow rate

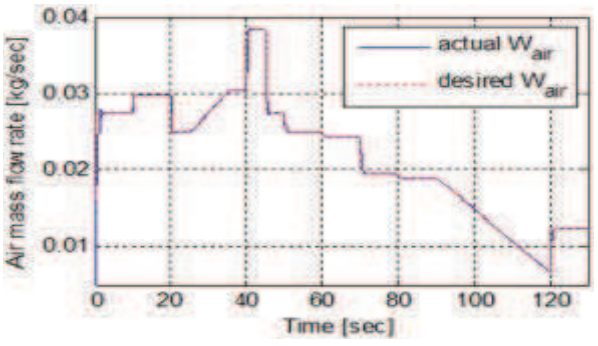

(b) Air mass flow rate

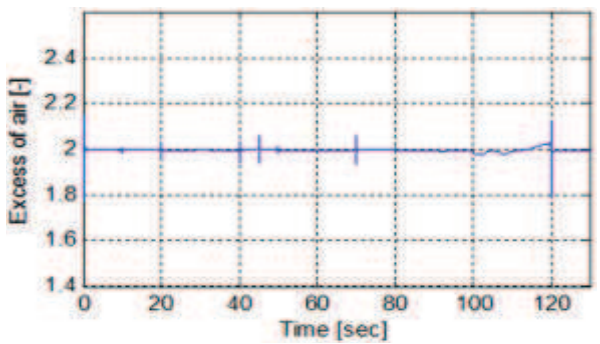

(d) Excess of air

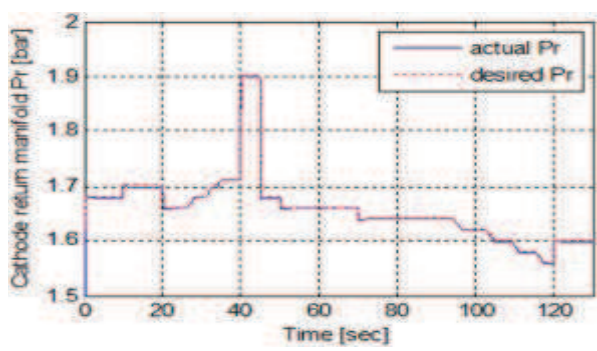

(f) Cathode pressure

Fig. 17. Response of Baseline rule-based controller ( $a, b$, and $c)$ and Baseline with feedforward component (d, e, and f).

shows a schematic for the addition of feedforward component, with proportional gain.

Figure $17(\mathrm{~d}, \mathrm{e}$, and $\mathrm{f})$ shows the results obtained using this final control architecture. Compared to the Baseline scheme, the air mass flow rate response is now faster, since it takes 0.1 seconds for $5 \%$ settling time. Also, the transient spikes in the cathode return manifold pressure response have been successfully eliminated; this was a particularly difficult issue for all of the techniques used in this study. The air excess ratio response for this scheme is particularly good, essentially achieving a value of 2 throughout, with a maximum excursion of 0.2 at $t=120$ seconds.

In addition to the desirable performance on the nonlinear truth model, one of the major advantages of using the rule-based controller is the fact that an observer (to estimate system states) is not needed. On the other hand, a drawback is that more calculations are needed in computing the implied fuzzy sets and the final control input value (Passino \& Yurkovich, 
1998); this effect is evident if we compare the time needed for these simulations compared to the simulations of the gain scheduled controller (roughly a factor of three different). Another disadvantage is the add-hoc nature of this technique, requiring the designer to be familiar with the system in order to efficiently tune the membership functions to achieve the best performance. However, experience gained in the linear and gain-scheduled control designs is useful here.

\section{Performance comparison}

Although the controllers developed heretofore performed well in simulation on the nonlinear truth model, which contains a variety of nonlinearities and maps, an important consideration is the capability of the controllers to perform adequately in the presence of realistic disturbances and uncertainties that may be experienced in typical operation. In this section, we consider three types of uncertainties that are typically not predicted by a model: disturbances, unmodeled dynamics (time delay), actuator limits, and input noise. In the analysis of this section, we compare the final (observer-based) gain-scheduled-interpolated controller with the final rule-based controller. Although there are several quantities of interest in the fuel cell system as a whole, these comparative studies will focus on the response of the compressor air mass flow, the cathode return manifold pressure, and the excess of air, because these are the most important variables in this PEM-FC model.

\subsection{Disturbances}

It is well known that the ionic conductivity of the membrane in a PEM-FC system is dependent upon its water content (McKay et al., 2005). Recall that for the model of this study, the inlet humidity level was considered constant at 0.6. Thus, a critical disturbance to consider for this model and the subsequent control design is uncertainty (disturbance) in the inlet humidity level, which directly affects the plant input. The response to significantly increased (or decreased) humidity levels, from the value assumed in the model-based control design, would be expected to degrade somewhat; the degree of degradation for each control scheme developed is of concern in this section.

First for the gain-scheduled control scheme developed earlier, we investigate the effect of changing the humidity inlet input to the FC-Model response by examining two values, 0.4 and 0.8 , representing a 33\% decrease and increase, respectively. Figure $18(a, b$, and c) shows the response of the system with 0.4 and 0.8 inlet humidity input (in separate traces on the same sizes). Clearly, the air mass flow rate was not affected by changing the inlet humidity because the compressor air mass flow rate is measured before the humidification process. However, an effect is evident on the cathode return manifold pressure. When the relative humidity is less than the value for which the control was designed (0.4 versus 0.6$)$, a pressure lower than the desired response results; the effect is opposite for the higher humidification case. This is expected, since the cathode return manifold pressure mainly depends on the cathode pressure, which is affected by the inlet humidity level. The effect is manifested in steady state errors that reach $1.5 \%$, as well as in a pronounced increase in transient spikes. Furthermore, the overshoot in the return manifold pressure reaches $11.3 \%$ in some transients. The excess air ratio is not affected since it depends on the response of the air mass flow rate. The same arguments apply when the inlet humidity level is increased to 0.8 , except that the steady state errors are smaller, but higher overshoot occurs in both the return manifold pressure and the excess of air response.

The rule-based control copes with an inlet humidity level disturbance much better than the 


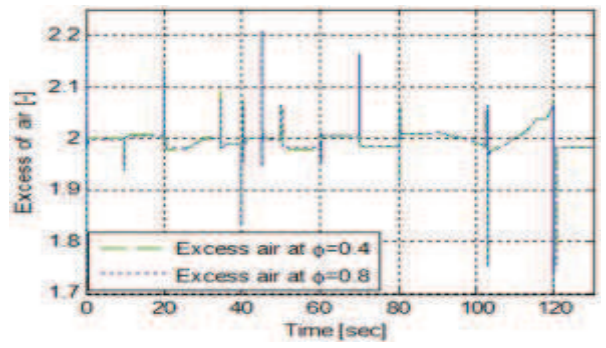

(a) Excess of air

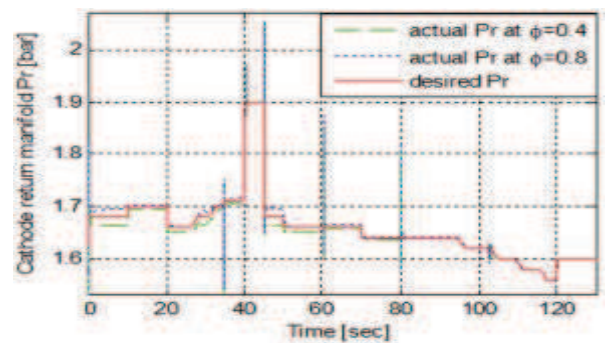

(c) Cathode pressure

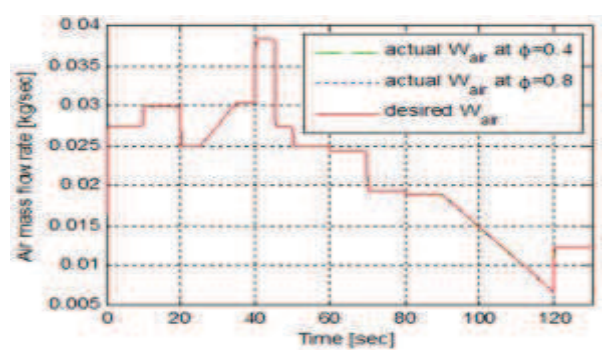

(e) Air mass flow rate

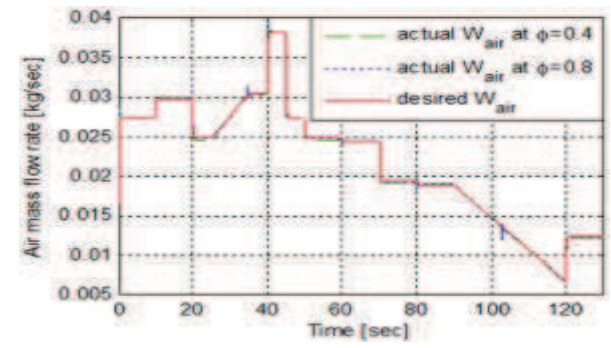

(b) Air mass flow rate

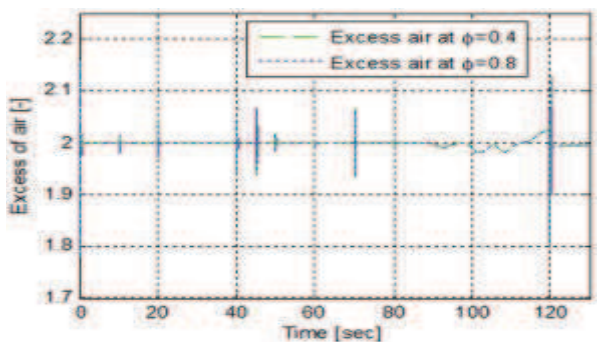

(d) Excess of air

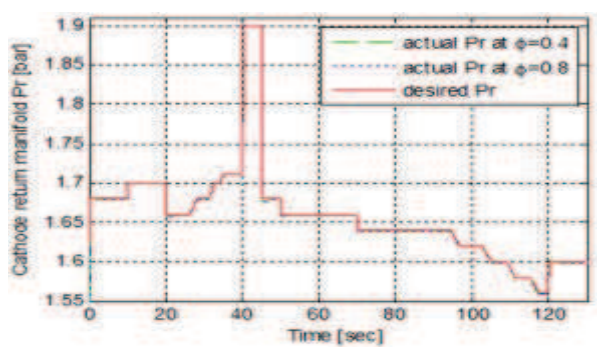

(f) Cathode pressure

Fig. 18. Response of gain-scheduled control (a, b, and c) and rule-based control (d, e, and f) with disturbance

gain scheduled control. Figure 18 (d, e, and f) shows the response for both cases, 0.4 and 0.8 inlet humidity levels. The increased performance of this scheme is evident in terms of the cathode return manifold pressure response. The steady state error is less than $0.1 \%$ and the overshoot is less than $3 \%$, which is very good considering the size of the disturbance. The excess air ratio was not affected, since it depends on the response of the air mass flow rate.

\subsection{Unmodeled dynamics (time delay)}

Unmodeled dynamics represented by a time delay due in the sensor dynamics will now be introduced and simulated. In this implementation, the time delay has been added to both outputs (compressor air flow rate and cathode return manifold pressure) before being fed to the observer (in the case of the gain scheduling scheme) and before being fed to the control decision blocks (in the case of the rule-based control scheme). 


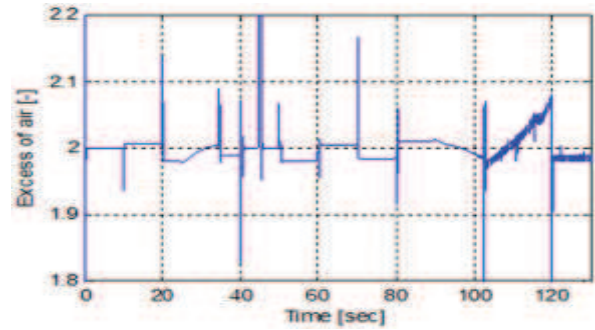

(a) Excess of air

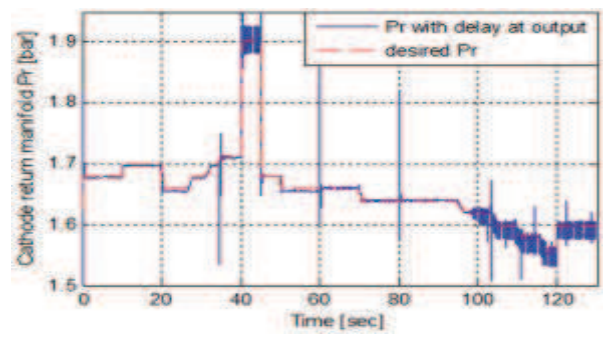

(c) Cathode pressure

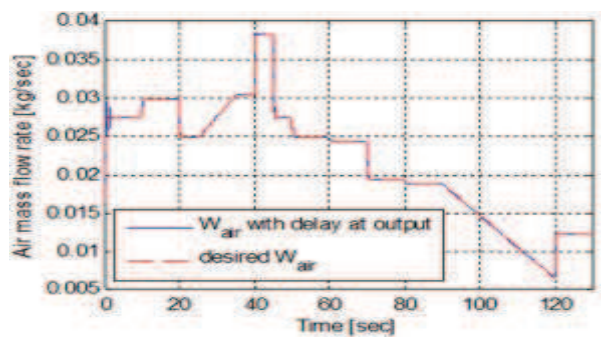

(e) Air mass flow rate

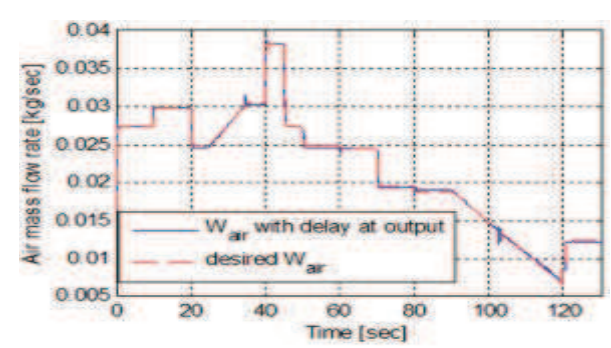

(b) Air mass flow rate

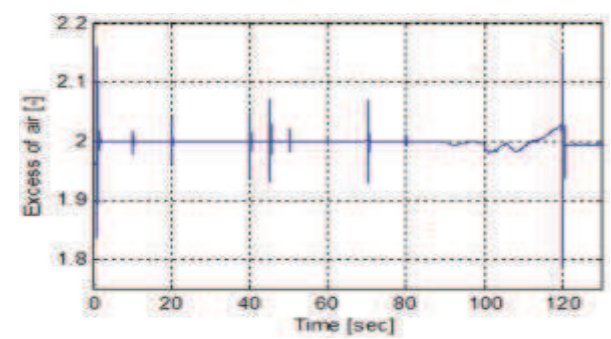

(d) Excess of air

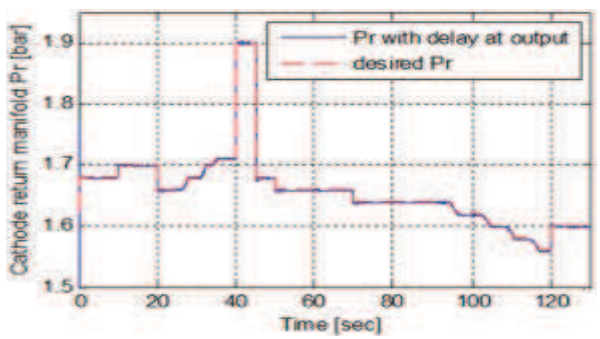

(f) Cathode pressure

Fig. 19. Response of gain-scheduled control (a, b, and c) and rule-based control (d, e, and f) with sensor time delay.

The delay is gradually increased until the gain schedule controller scheme started to exhibit unstable behavior. The maximum sensor delay reached, while still exhibiting a reasonable response, is 10 milliseconds. The controller is sluggish, and noticeable transient spikes can be observed in Figure 19 (a, b, and c). On the other hand, for the rule-based controller, the same time delay applied to the sensors once again results in comparatively good behavior in the presence of this uncertainty. Figure 19 (d, e, and f) shows the response, where only small fluctuations in the pressure response are evident, which does not exceed $1 \%$ of the steady state value.

\subsection{Actuator limits}

The final robustness test in this study investigates controller performance when the actuators undergo some limitation in authority. Two experiments are performed; the first assumes that 


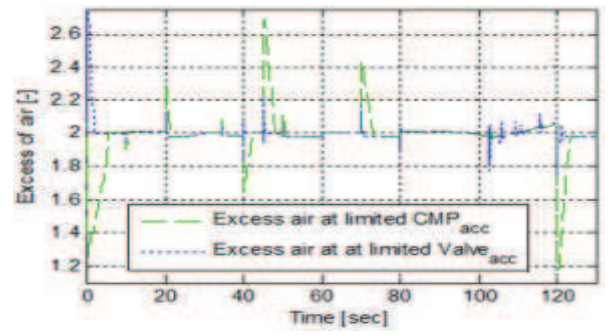

(a) Excess of air

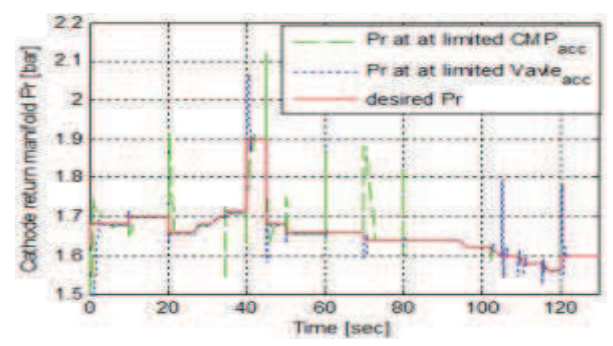

(c) Cathode pressure

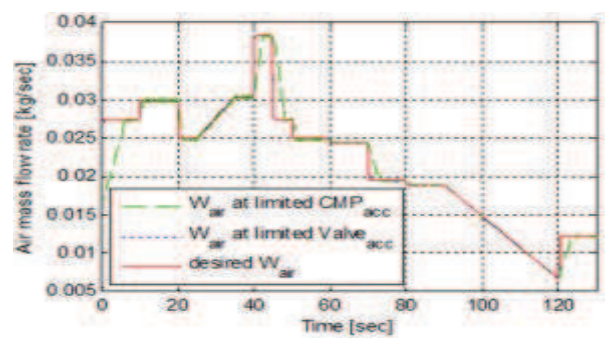

(e) Air mass flow rate

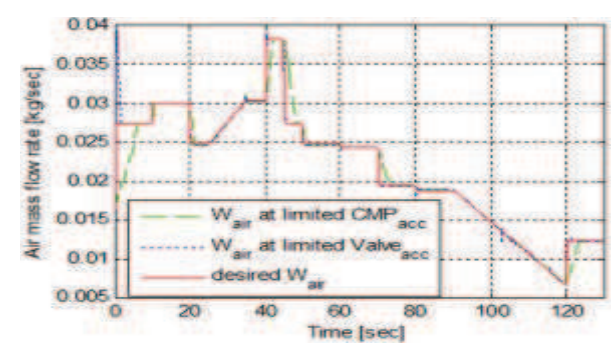

(b) Air mass flow rate

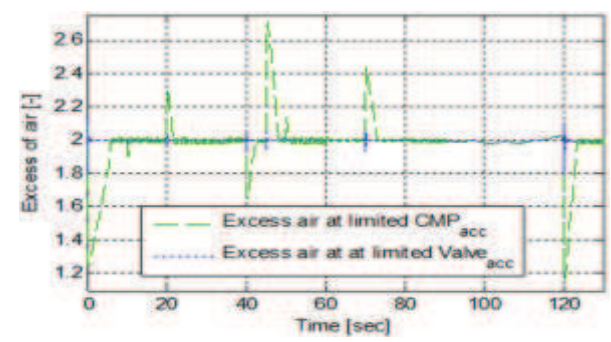

(d) Excess of air

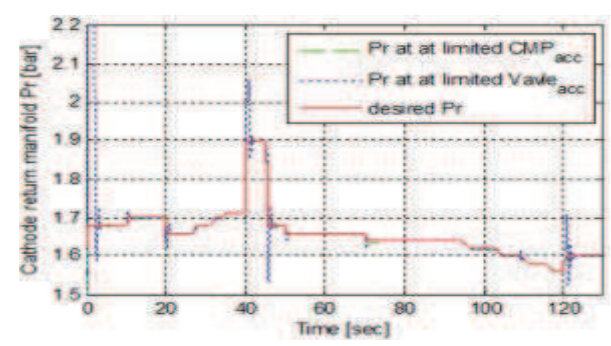

(f) Cathode pressure

Fig. 20. Response of gain-scheduled control (a, b, and c) and rule-based control (d, e, and f) with actuator limits.

the compressor response is slower than the modeled speed-driven screw compressor, where the acceleration of the compressor was limited to $200 \mathrm{RPM} / \mathrm{s}$. The second experiment assumes that the valve opening rate is limited to $25 \%$ per second.

Consider first the observer based gain-scheduled controller. Figure 20 (a, b, and c) are reasonable, where two traces (one for limited compressor response, CMP, and the other for valve opening rate). As we mentioned earlier, the compressor air flow and the cathode return manifold pressure both have a mild coupling. Therefore, we notice that when we limited the compressor acceleration, the air mass flow rate was affected much more than the return manifold pressure. Limiting the valve opening acceleration affected the compressor air flow rate, but only slightly. Nevertheless, it did clearly affect the return manifold pressure, especially at the transients where we see spikes that did not exist before. Notice also the spikes observed in the excess air ratio response; the compressor is not able to provide the air needed 
as fast as the FC desires, and effect which could harm the stack and reduce the durability of the FC.

Applying the same two parametric uncertainty experiments to the system controlled by a rule-based controller results in the traces shown in Figure 20 (d, e, and f). When limiting the compressor acceleration, a slow response in the air flow results as in the case of gain-scheduled control system. However, limiting the valve opening acceleration results in fewer transient spikes compared to the gain-scheduled controller. The excess air ratio behavior is reasonable under this uncertainty, although we should point out that limiting the compressor acceleration will affect the air flow rate and therefore the excess air ratio. In fact, neither controller completely overcame this uncertainty.

\subsection{Input noise}

The last robustness test is to check the effect of the noise. To achieve this, random number generators are added to the FC system input signals. The parameters of the noise generated are chosen to be zero mean with the variance equal to $3 \%$ of input steady state values at $\mathrm{I}=80 \mathrm{~A}$. This time, the responses for both control techniques are plotted on the same axes to make the comparison easier. From Figure 21, it is clear that the rule-based controller is more robust to input noise than the gain-scheduling controller. This is clear in all of the responses, especially the cathode return manifold pressure and the excess air. For the rule-based response, we do not see large spikes and the variance of the response from the desired trajectory is not large compared to the response of the gain-scheduled controller.

\section{Conclusion}

Beginning with a highly nonlinear model, a simplified, reduced-order control-oriented model was obtained by linearizing about a nominal operating point. We then investigated linear

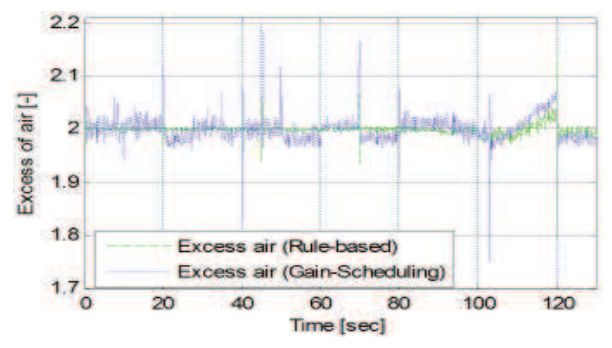

(a) Excess of air

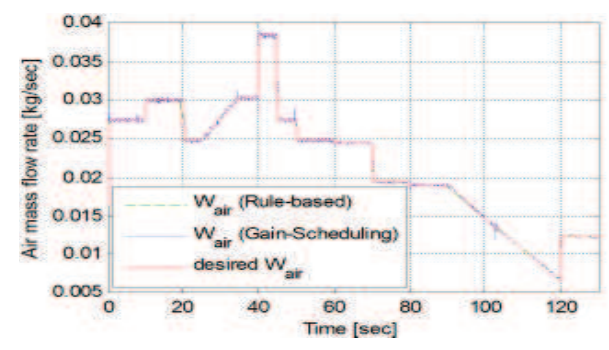

(b) Air mass flow rate

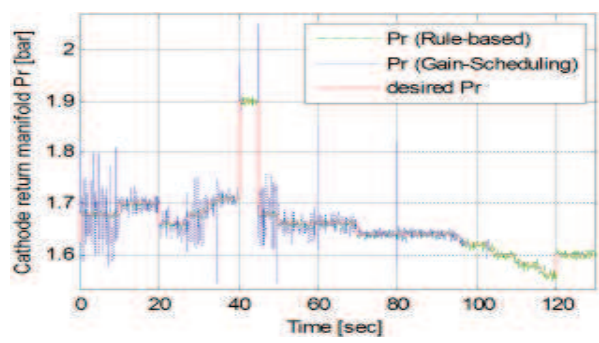

(c) Cathode pressure

Fig. 21. The response of both controllers with input noise. 
quadratic regulator control, with observer, for the reduced-order model, where shortcomings due to the limited range of the linearization were evident. This led to the concept of gain scheduling control, introduced for this architecture to allow operation in a wider range. Simulation results showed that this technique does, indeed, allow a wider range of operation; however, as expected, transient spikes appeared due to the fast switching in the region of operation. Two methods were used to reduce theses spikes: interpolating the controller gains, and reshaping the input trajectory. The two techniques reduce the undesirable behavior considerably, but the response still has overshoot during the transients because of the fast switching between regions of operation. A rule-based, output feedback control, was implemented with fuzzy logic and coupled with a nonlinear feed-forward approach. The resulting control system was examined under the same conditions applied to the first two techniques. The rule-based controller achieved the best results in terms of the speed of response and overall performance during the transients. Robustness of the gain-scheduled control and the rule-based control to disturbance, time delay, actuators limits, and input noise was investigated. Overall, the rule-based controller performed very well when the system was subjected to these effects.

The contributions of this study include a high fidelity nonlinear model of a typical fuel cell system (intended for automotive applications), formulation of a reduced order, control-oriented mode suitable for modern control design, nonlinear control designs offered in comparison, and a performance study for a range of uncertainties expected in typical system operation. The control design methodologies chosen for comparison are straightforward and effective, in keeping with the over riding intent of the work to maintain designs which would be readily applied to an actual system.

\section{References}

Al-Durra, A., Yurkovich, S. \& Guezennec, Y. (2007). Gain-Scheduled Control for an Automotive Traction PEM Fuel Cell System, Proceedings of the 2007 ASME International Mechanical Engineering Congress and Exposition .

Al-Durra, A., Yurkovich, S. \& Guezennec, Y. (2010). Study of Nonlinear Control Schemes for an Automotive Traction PEM Fuel Cell System, International Journal of Hydrogen Energy (doi:10.1016/j.ijhydene.2010.07.046).

Ambühl, D., Anguiano, N., Sorrentino, M., Y. Guezennec, S. M. \& Rizzoni, G. (2005). 1\&1D Isothermal Steady State Model of a Single PEM Fuel Cell, Proceedings of 2005 IMECE, Orlando, FL, U.S.A.

Arsie, I., Di-Domenico, A., Pianese, C. \& M.Sorrentino (2005). Transient Analysis of PEM Fuel Cell for Hybrid Vehicle Application, Proceedings of 2005 ASME 3rd Int. Conference on Fuel Cell Science, Ypsilanti, MI .

Bansal, D., Rajagopalan, S., Choi, T., Guezennec, Y. \& Yurkovich, S. (2004). Pressure and Air Fuel Ratio Control of PEM Fuel Cell System for Automotive Traction, IEEE - VPP conference.

Bernay, C., Marchanda, M. \& Cassir, M. (2002). Prospects of Different Fuel Cell Technologies for Vehicle Applications, Journal of Power Sources 108 pp. 139-152.

Brinkman, N. (2002). Well to Wheel Energy Use and Greenhouse Gas Emission of Advanced Fuel/Vehicle System - North American Analysis, General Motors Executive Summary Report, available at the http://www.epa.gov pp. 139-152.

Chen, D. \& Peng, H. (2004). Modeling and Simualtion of a PEM Fuel Cell Humidification System, Proceeding og the 2004 American Control Conference. 
Davis, C., Edelstein, B., Evenson, B. \& Brecher, A. (2003). Hydrogen Fuel Cell Vehicle Study, American Physical Society Report available at the http://www.aps.org .

Domenico, A., Miotti, A., Alhetairshi, M., Guezennec, Y., Rajagopalan, S. \& Yurkovich, S. (2006). Multi-Variable Control for Automotive Traction PEM Fuel Cell System, IEEE American Control Conference .

EG\&G-Technical-Services (2002). Fuel Cell Handbook-Sixth edition, U.S. Department of Energy - National Energy Technology Laboratory Strategic Center for Natural Gas.

Fortgang, J. \& Singhose, W. (2002). Concurrent Design of Input Shaping and Vibration Absorbers, Proceeding of American Control Conference pp. 1491-1496.

Franklin, G., Powell, J. \& Workman, M. (1990). Digital Control of Dynamic Systems, Addison-Wesley.

Guzzella, L. (1999). Control Oriented Modeling of Fuel Cell Based Vehicles, NSF Workshop on the Integration of Modeling and Control for Automotive System .

Heywood, J. (1998). Internal Combustion Engine Fundamentals, McGraw Hill.

Kueh, T., Ramsey, J. \& Threlkeld, J. (1998). Thermal Enviromental Engineering, McGraw Hill.

Larminie, J. \& Dicks, A. (2003). Fuel Cell System Explained, Wiley.

Mazunder, S. (2003). A Generalized Phenomenological Model and Database for the Transport of Water and Current in Polymer Electrolyte Membranes, Journal of Electrochemical Society.

McKay, D., Ott, W. \& Stefanopoulou, A. (2005). Modeling, Parameter Identification, and Validation of Reactant and Water Dynamics for a Fuel Cell Stack, Proc. of IMECE

Miotti, A., Domenico, A., Esposito, A. \& Y. Guezennec, Y. (2006). Transient Analysis and Modeling of Automotive PEM Fuel Cell System Accounting for Water Transport Dynamics, Proc. of ASME 2006 4th International Conference on Fuel Cell Science, Engineering and Technology .

Passino, K. \& Yurkovich, S. (1998). Fuzzy Control, Addison-Wesley.

Pukrushpan, J. (2003). Modeling and Control of Fuel Cell System and Fuel Processor, PhD thesis, The University of Michigan, Ann Arbor, U.S.A.

Pukrushpan, J., Stefanopoulou, A. \& Peng, H. (2002). Modeling and Control for PEM Fuel Cell Stack System, Proceeding of American Control Conference pp. 3117-3122.

Pukrushpan, J., Stefanopoulou, A. \& Peng, H. (2004a). Control of Fuel Cell Breathing, IEEE Control Systems Magazine .

Pukrushpan, J., Stefanopoulou, A. \& Peng, H. (2004b). Control of Fuel Cell Breathing: Initial Results on the Oxygen Starvation Problem, IEEE Control Systems Magazine 24: 30-46.

Pukrushpan, J., Stefanopulou, A. \& Peng, H. (2002). Modeling and Control for PEM Fuel Cell Stack System, Proceeding of American Control Conference pp. 3117-3122. Anchorage,AK.

Pukrushpan, J., Stefanopulou, A. \& Peng, H. (2004). Simulation and Analysis of Transient Fuel Cell System Performance Based on Dynamic Reactant Flow Model, Proceedings of 2002 ASME International Mechanical Engineering Conference and Exposition.

Rodatz, P. (2003). Dynamics of the Polymer Electrolyte Fuel Cell: Experiments and Model-Based Analysis, PhD thesis, Swiss Federal Institute of Technology, Zurich, Swiss.

Rugh, W. \& Shamma, J. (2000). Survey Paper: Research on Gain Scheduling, Automatica 36: 1401-1425.

Shamma, J. \& Athans, M. (1992). Gain Scheduling: Potential Hazards and Possible Remedies, IEEE Control Systems Magazine. 
Thijssen, J. \& Teagan, W. (2002). Long-Term Prospects for PEMFC and SOFC in Vehicle Applications, SAE paper 2002-01-0414 .

Thomas, S. \& Zalbowitz, M. (2000). Fuel Cells Green Power, Los Alamos National Laboratory .

Tzes, A. \& Yurkovich, S. (1993). An Adaptive Input Shaping Control Scheme for Vibration Suppression in Slewing Flexible Structures, IEEE Transactions on Control Systems Technology 1: 114-121.

Yi, J., Yang, J. D. \& King, C. (2004). Water Management Along the Flow Channels of PEM Fuel Cells, AIChE Journal .

Yu, Q., Srivastava, A., Choe, S. \& Gao, W. (2006). Improved Modeling and Control of a PEM Fuel Cell Power System for Vehicles, Proceedings of the IEEE SoutheastCon . 


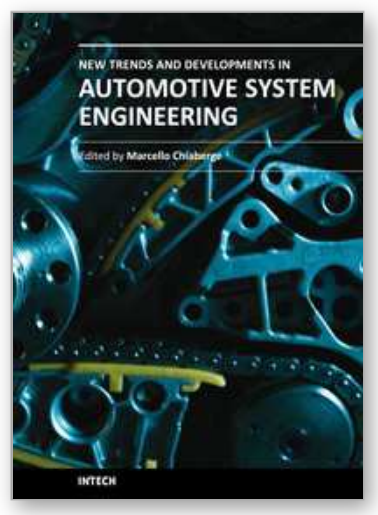

\author{
New Trends and Developments in Automotive System Engineering \\ Edited by Prof. Marcello Chiaberge
}

ISBN 978-953-307-517-4

Hard cover, 664 pages

Publisher InTech

Published online 08, January, 2011

Published in print edition January, 2011

In the last few years the automobile design process is required to become more responsible and responsibly related to environmental needs. Basing the automotive design not only on the appearance, the visual appearance of the vehicle needs to be thought together and deeply integrated with the â€œpowerâ€ developed by the engine. The purpose of this book is to try to present the new technologies development scenario, and not to give any indication about the direction that should be given to the research in this complex and multi-disciplinary challenging field.

\title{
How to reference
}

In order to correctly reference this scholarly work, feel free to copy and paste the following:

Ahmed Al-Durra, Stephen Yurkovich and Yann Guezennec (2011). On the Control of Automotive Traction PEM Fuel Cell Systems, New Trends and Developments in Automotive System Engineering, Prof. Marcello Chiaberge (Ed.), ISBN: 978-953-307-517-4, InTech, Available from: http://www.intechopen.com/books/newtrends-and-developments-in-automotive-system-engineering/on-the-control-of-automotive-traction-pem-fuelcell-systems

\section{INTECH}

open science | open minds

\section{InTech Europe}

University Campus STeP Ri

Slavka Krautzeka 83/A

51000 Rijeka, Croatia

Phone: +385 (51) 770447

Fax: +385 (51) 686166

www.intechopen.com

\section{InTech China}

Unit 405, Office Block, Hotel Equatorial Shanghai

No.65, Yan An Road (West), Shanghai, 200040, China

中国上海市延安西路65号上海国际贵都大饭店办公楼405单元

Phone: +86-21-62489820

Fax: +86-21-62489821 
(C) 2011 The Author(s). Licensee IntechOpen. This chapter is distributed under the terms of the Creative Commons Attribution-NonCommercialShareAlike-3.0 License, which permits use, distribution and reproduction for non-commercial purposes, provided the original is properly cited and derivative works building on this content are distributed under the same license. 